\title{
SPACE WEATHER: RISK FACTORS FOR GLOBAL NAVIGATION SATELLITE SYSTEMS
}

\section{V.V. Demyanov}

Institute of Solar-Terrestrial Physics SB RAS,

Irkutsk,Russia,vv.emyanov@gmail.com

Irkutsk State Transport University,

Irkutsk,Russia,vv.emyanov@gmail.com

\author{
Yu.V. Yasyukevich \\ Institute of Solar-Terrestrial Physics SB RAS, \\ Irkutsk, Russia,yasukevich@iszf.irk.ru
}

Abstract. Extreme space weather events affect the stability and quality of the global navigation satellite systems (GNSS) of the second generation (GPS, GLONASS, Galileo, BeiDou/Compass) and GNSS augmentation. We review the theory about mechanisms behind the impact of geomagnetic storms, ionospheric irregularities, and powerful solar radio bursts on the GNSS user segment. We also summarize experimental observations of the space weather effects on GNSS performance in 2000-2020 to confirm the theory. We analyze the probability of failures in measurements of radio navigation parameters, decrease in positioning accuracy of GNSS users in dual-frequency mode and differential navigation mode (RTK), and in precise point positioning (PPP). Additionally, the review includes data on the occurrence of dangerous and extreme space weather phenomena and the possibility for predicting their impact on the GNSS user segment.

The main conclusions of the review are as follows: 1) the positioning error in GNSS users may increase up to 10 times in various modes during extreme space weather events, as compared to the background level; 2) GNSS space and ground segments have been significantly modernized over the past decade, thus allowing a substantial increase in noise resistance of GNSS under powerful solar radio burst impacts; 3 ) there is a great possibility for increasing the tracking stability and accuracy of radio navigation parameters by introducing algorithms for adaptive lock loop tuning, taking into account the influence of space weather events; 4) at present, the urgent scientific and technical problem of modernizing GNSS by improving the scientific methodology, hardware and software for monitoring the system integrity and monitoring the availability of required navigation parameters, taking into account the impact of extreme space weather events, is still unresolved.

Keywords: space weather, GNSS, GPS, GLONASS, solar flares, magnetic storms, scintillations, PPP, RTK.

\section{CONTENT}

\begin{tabular}{|c|c|c|}
\hline & Terminology in use... & 29 \\
\hline & 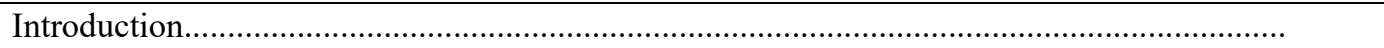 & 30 \\
\hline 1. & Impact of solar radio bursts on GNSS performance & 31 \\
\hline 1.1. & 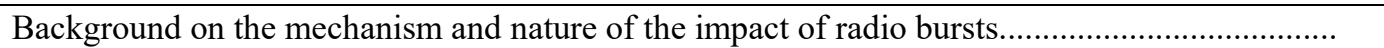 & 31 \\
\hline 1.2. & 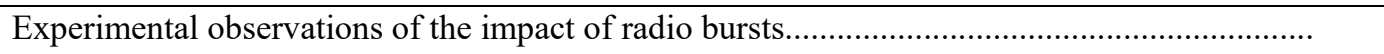 & 32 \\
\hline 2. & 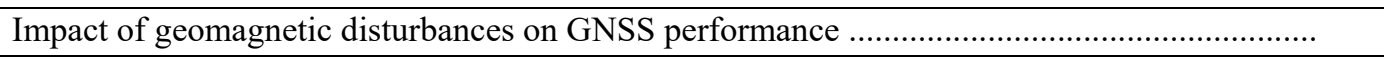 & 36 \\
\hline 2.1. & 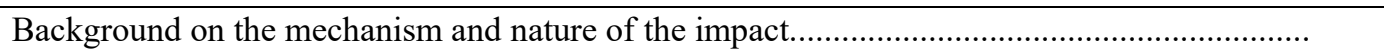 & 36 \\
\hline 2.2. & Experimental observations of the impact of geomagnetic disturbances ….................................. & 37 \\
\hline 3. & 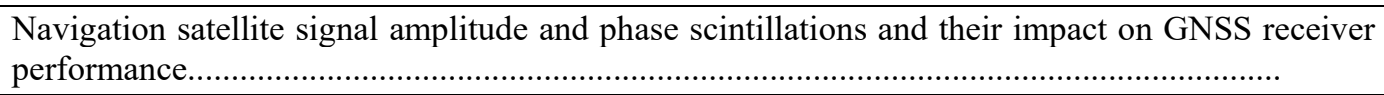 & 37 \\
\hline 3.1. & 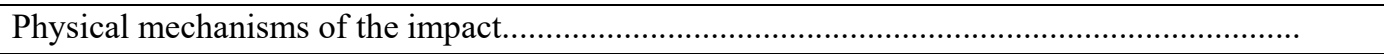 & 37 \\
\hline 3.2. & Experimental observations of the scintillation impact................ & 39 \\
\hline 4. & 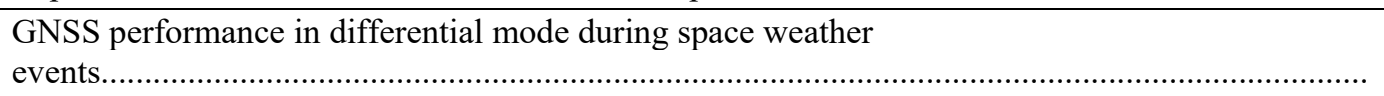 & 39 \\
\hline 4.1. & Physical mechanisms of the impact...... & 39 \\
\hline 4.2. & 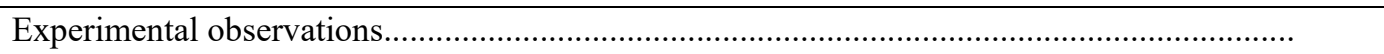 & 40 \\
\hline
\end{tabular}




\begin{tabular}{|c|c|c|}
\hline 5. & Intensity and rate of occurrence of extreme space weather events critical for GNSS perfor- & 41 \\
\hline 5.1. & 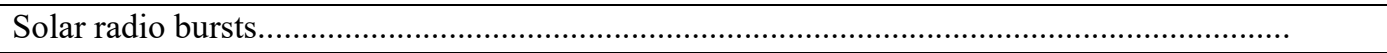 & 41 \\
\hline 5.2. & $\begin{array}{l}\text { Magnetic } \\
\text { storms....................................... }\end{array}$ & 42 \\
\hline & Conclusions. & 43 \\
\hline
\end{tabular}

\section{TERMINOLOGY IN USE}

Since the article contains information from various fields of knowledge, we define the terms needed to better understand the text. Terminology is not given in alphabetical order, but is divided into semantic blocks.

Global Navigation Satellite Systems (GNSS) are the second generation satellite radio navigation systems using medium (as the basis) and geostationary orbits of navigation satellites to address problems of Positioning, Velocity, and Time (RVT) in the global coverage area. There are currently four GNSS: GPS (USA), GLONASS (RF), Galileo (EU), BeiDou/Compass (PRC). A set of satellites in orbits is a navigation constellation. GNSS have the main operating frequency designed for open use in the mode of standard RVT accuracy and auxiliary frequencies used for more accurate measurements. In particular, modern GPS navigation satellites emit navigation signals in three frequency bands (L1, L2, L5).

GNSS augmentations (systems of local and wide-area navigation/correction) are ground-based and space-born augmentation systems, which within their coverage areas form differential corrections to ranging and positioning errors as well as provide additional information for monitoring GNSS integrity and availability of Required Navigation Parameters (RNP).

GNSS user is a user of GNSS and (or) GNSS augmentation equipped with a navigation receiver, a GNSS user's device (receiver) for obtaining user's PVT (Position, Velocity and Time) by processing signals from GNSS and its augmentations.

PVT means the user's position, velocity, and time determination: coordinates, velocity vector components, and GNSS time offsets. User's PVT can be determined in two main modes - standalone positioning and differential (or relative) positioning. Moreover, there are Standard Point Positioning (SPP) and Precise Point Positioning (PPP). In the latter case, PVT determination involves using additional methods and means for post-processing based on measurement integration and error corrections. The PPP mode features a long convergence time, which makes it particularly susceptible to signal loss of lock at the stage of PVT determination.

Standalone GPS, Standard Point Positioning, is a mode of usage of only GNSS signals for PVT determination without additional navigation data sources to refine user's PVT parameters.

Differential GPS, Real Time Kinematic (RTK) is a mode of combined usage of GNSS signals and additional control-correcting signals from a reference station (network) of GNSS augmentation with known coordinates. Differential GPS allows us to estimate user's PVT parameters with higher accuracy by correcting ranging errors for all GNSS satellites in view (pseudorange correction mode) or by direct correction of object coordinates (coordinate correction mode).

Ranging parameter is a navigation satellite signal parameter that can be directly measured by radio-technical means. As ranging parameters GNSS use a code pseudodelay satellite-receiver, carrier pseudophase, and Doppler pseudofrequency (prefix "pseudo" denotes the corresponding parameter measured with errors).

Navigational parameter is a value uniquely related to the ranging parameter and allowing us to estimate user's PVT parameters. In particular, the code pseudorange is equal to the code pseudodelay multiplied by the speed of light; the phase pseudorange is equal to the pseudophase multiplied by the wavelength.

Required Navigation Parameters (RNP) are directively preset maximum values of absolute errors in determining user's PVT parameters, GNSS availability and integrity.

GNSS integrity is the probability of warning a user about malfunction in the system or in some of its segments for a specified time period. od.

GNSS availability is the probability of maintenance of required navigation parameters for a specified time peri-

Positioning error is a deviation of measured coordinate from its true value in a given coordinate system. Errors are generally classified as follows: horizontal plane error, height error, and full three-dimensional error (3D).

Positioning failure is an event when the error in estimating one or more object coordinates exceeds maximum values or when there is no information on current object coordinates.

L1 (L2) ranging failure implies the appearance of an abnormal value or lack of instantaneous measurement of this parameter. In phase measurements, the cycle slip is a discontinuity in receiver's phase tracking, and the loss of lock means a GNSS receiver no longer tracks the signal phase for a time.

Space weather is a combination of heliogeophysical events affecting technological systems and facilities, including satellites, and biological objects. In relation to GNSS, this term is applied to extreme phenomena that, inter alia, affect radio wave propagation conditions and lead to the occurrence of induced currents, such as strong magnetic 
storms, intense ionospheric irregularities (which give rise to scintillations of transionospheric signals), and powerful solar radio bursts in the GNSS operating frequency band.

Ionospheric scintillations are random rapid variations in carrier amplitude and phase of a navigation satellite due to signal scattering by small-scale electron density (ED) irregularities in the ionosphere (mainly in the vicinity of the ED maximum in the ionospheric F layer). For GNSS, individual terms are frequently used: phase scintillations random short-term abrupt phase variations and amplitude scintillations - random short-term sharp variations in received signal strength.

Magnetic storm is an extreme process in near-Earth space that features a long-term (from several hours to several days) geomagnetic disturbance. The main source of magnetic storms is coronal mass ejections and high-speed solar particle fluxes, which, when reaching Earth's immediate environment, cause geomagnetic field lines to compress. Magnetic storms are accompanied by a significant restructuring of the neutral atmosphere and the ionosphere, as well as by energetic particle precipitation in the upper atmosphere, auroras, and generation of electron density irregularities of various scales in the ionosphere.

Solar radio burst is a considerable short-term increase in solar flux in a radio range from tens of megahertz to tens of gigahertz. What is the most critical for GNSS performance is the solar radio burst in the operating frequency band 1-2 GHz of these systems.

\section{INTRODUCTION}

In the years since the commissioning of the first global navigation satellite systems (GNSS) GPS (USA, 1980) and GLONASS (USSR, 1990), the number of practical and scientific applications of satellite navigation has continuously increasing at a very quick rate. Today there are two more GNSS - Galileo (EU) [Galileo-SIS-ICD, 2021] and BeiDou/Compass (China) [BDS-SIS-ICD, 2019]. Regional navigation satellite systems QZSS (Japan) are being commissioned [https://qz ss.go.jp/en/technical/download/pdf/ps-isqzss/is-qzss-16-001.pdf and GAGAN/NavIC/IRNSS (India) [https://www.isro.gov.in/sites/default/files/irnss sps icd version1.1-2017.pdf] At the same time, a segment of ground-based and space-born GNSS wide area augmentation systems is being developed. The Wide Area Augmentation Systems (WAAS, USA) [GPS-WAAS-PS, 2008], the European Geostationary Navigation Overlay System (EGNOS, EU) [Falcone et al., 2006], BeiDou (China) [Shi, Liu, 2006], as well as the Regional System of Differential Correction and Monitoring (RSDCM, Russia) [IKD SDKM, 2012] have been put into operation.

The applied use of GNSS has led to an expansion of geodynamic and geophysical monitoring networks. Over the past 20 years, numerous measuring GNSS networks and data processing centers, employed for metrological maintenance of GNSS, for solving scientific and research problems and problems of applied geodesy, such as the Network of International Geophysical GNSS Service (IGS) [Dow et al., 2009]; UNAVCO [Freymueller, 2017]; EUREF [Bruyninx et al., 2012]; CHAIN [Jayachandran et al., 2009], SONEL [https:// www.sonel.org], etc., have been deployed around the world. There are Continuously Operating Reference Stations (CORS) of different departmental subordination, including those in the territory of the Russian Federation [Vdovin et al., 2018], for example, HIVE [https://hive.geosystems.aero], EFT-CORS [https://eftcors.ru], etc. GNSS data is generally stored on a network server in the standard format RINEX (Receiver INdependent EXchange) [https://kb.igs.org/hc/en-us/articles/ 201096516-IGS-Formats] and in most cases may be freely used for scientific-research and designengineering purposes.
Even today, the aforementioned technological facilities and systems furnish an opportunity to achieve millimeter positioning accuracy almost anywhere in the world. In the standalone positioning mode in the global coverage area, the positioning error is a few meters, with more than $99 \%$ of positioning availability. It is evident that nowadays the transition from quantity to quality occurs - formation of an integrated worldwide global navigation system ensuring unprecedented accuracy, continuity and integrity of PVT (Position, Velocity and Time) of any kinematic and static objects in the global coverage area at a sharp fall in prices for respective GNSS services.

At the same time, unique opportunities open up for the use of GNSS signals to explore near-Earth space, the atmosphere, the ocean, and Earth's surface from space. In particular, an important avenue of research is the remote sensing of Earth's ionosphere and atmosphere. The interaction chain earth's crust atmosphere - ionosphere - magnetosphere - interplanetary medium - the Sun is a unified system, and the ionosphere and the atmosphere in these frameworks may be regarded as sensitive indicators of the state of geospheres and used to devise effective systems for early earthquake, tsunami, and cyclone activity alerts. Global ionospheric maps of total electron content (TEC) and its variations offer opportunities for climatology studies of the ionosphere and ionospheric irregularities on a global scale [Hernandez-Pajares et al., 2009; Yasyukevich et al., 2020a]. Today, such areas of geophysical studies are being actively developed as GNSS radio occultation (GNSS-RO), GNSS reflectometry of Earth's surface and ocean (GNSS-R), remote sensing of the ionosphere and the atmosphere on the basis of GNSS technologies [Jin et al., 2014].

From the above we can state that GNSS (and directly related ground-based and space-born augmentation systems) have outgrown their original purpose - to facilitate navigation - and have become one of the leading factors in the international technological advances. Such significance of GNSS has a flip side unusually high operation and maintenance requirements for GNSS, including all segments and augmentations. One of the main factors responsible for the accuracy in 
measuring ranging parameters from GNSS signals is space weather.

The resulting applied scientific problem of ensuring the required quality of GNSS measurements in order to solve applied and research problems under conditions of extreme space weather events poses a fundamental scientific problem of identification and quantitative and qualitative assessment of prevailing radio physical and electronic mechanisms and factors behind GNSS performance deterioration.

The purpose of this survey paper is to analyze the current status of research on the aforementioned scientific and applied scientific problems in Russia and abroad. On the basis of its results, we suggest possible ways to improve scientific-methodological and hardware and software support for GNSS and their augmentations in terms of the impact of extreme space weather events.

\section{IMPACT OF SOLAR RADIO BURSTS ON GNSS PERFORMANCE}

\subsection{Background on the mechanism and na- ture of the impact of radio bursts}

The Sun is a source of electromagnetic emission in an extremely wide range of wavelengths, including the frequency band of GNSS signals (1-2 GHz, L-band). In the latter case, the Sun may act as a generator of strong electromagnetic interference jamming a desired signal from navigation satellites and leading to a sharp decrease in the signal-to-noise ratio at the input of the code and phase lock loops of a navigation receiver. Features of solar radio bursts in the L-band are:

1) quasiperiodic nature of increase and decrease in the number of radio bursts, statistically weakly related to the solar activity level [Huang et al., 2018];

2) inverse relationship between the rate of occurrence of a burst and its strength (the more intense is the burst, the less frequently it occurs, the more difficult it is to predict) [Michalek et al., 2009];

3) wide spread of duration and strength of bursts from seconds to tens of minutes and from $10^{2}$ to $10^{6}$ s.f.u. (solar flux unit, 1 s.f.u. $=10^{-22} \mathrm{~W} \cdot \mathrm{m}^{-2} \cdot \mathrm{Hz}^{-1}$ ) [Dulk, 1985; Michalek et al., 2009];

4) unpredictable type, form, and direction of solar electromagnetic wave polarization [Dulk, 1985];

5) weak correlation between X-ray and radio emission parameters [Dulk, 1985; Berghmans et al., 2005], which hinders the prediction of severe radio bursts.

Up to 2000, solar radio bursts have not been considered as a serious threat to smooth GNSS operation. Thus, Klobuchar et al. [1999] have estimated the potentially hazardous burst power level at 20000 s.f.u. with the right-hand circular polarization and at 40000 s.f.u. with another. These extreme events are fairly rare: over the period from 1997 to 2016 there were only 21 events when solar flux exceed 10000 s.f.u. [Huang et al., 2018], two most intense (>100000 s.f.u.) occurring one by one on December 6 and 13, 2006 and leading to serious GPS and WAAS disruptions [Afraimovich et al., 2009b; Carrano et al., 2007].
A more detailed analysis has shown less intense solar radio bursts can also exert a significant effect on GNSS performance. Chen et al. [2005] indicate that the threshold of the dangerous radio burst intensity should be lowered to 4000-12000 s.f.u. Demyanov et al. [2012a] have even more lowered this threshold, to 3000 s.f.u. A particular value of this threshold depends on the type of primary signal processing algorithms in a GNSS receiver [Linty, 2010; Demyanov et al., 2012a].

To develop ways for improving GNSS noise immunity and augmentations, it is important to know maximum values of solar radio emission power when employing different characteristics of radio-frequency chain and GNSS signal pre-processing algorithms. The phase tracking loop is known to be stable when the condition [Demyanov et al., 2012a]

$$
\begin{aligned}
& C N_{\mathrm{EQ}} \geq C N_{\mathrm{TR}}= \\
& =-10 \lg (\Delta T \sqrt{1+2 A /(\Delta T \Delta F)}-\Delta T), \\
& C N_{\mathrm{EQ}}=-10 \lg \left(10^{-0.1 C N R}+10^{0.1 J S} /\left(r Q F_{\mathrm{PRN}}\right)\right),
\end{aligned}
$$

holds, where $C N_{\mathrm{EQ}}$ is the equivalent signal-to-noise ratio at the input of the phase tracking loop under solar radio emission, $\mathrm{dB} \mathrm{W} ; C N_{\mathrm{TR}}$ is the threshold signal-to-noise ratio of tracking loop stability, $\mathrm{dB} \mathrm{W} ; \Delta T$ is the time of integration of quadrature signal components, $\mu \mathrm{s} ; \Delta F$ is the noise bandwidth of an antialiasing filter in the phase tracking loop, Hz; $A$ is the parameter dependent on the maximum permissible error in estimating the instantaneous phase in view of short-term frequency instability of the reference oscillator; $C N R$ is the signal-to-noise ratio at the input of the receiver in view of power losses in the atmosphere, antenna (polarization losses), and cable, but regardless of solar radio noise, $\mathrm{dB} \mathrm{W} ; Q$ is the parameter depending on the ratio of signal bandwidth to interference bandwidth $(Q=1$ for non-Gaussian narrowband interference; $Q=2$ for white Gaussian noise); $J S$ is the ratio of solar radio noise power to desired signal power, $\mathrm{dB} \mathrm{W} ; r$ is the coefficient accounting for losses caused by distortion of the $\mathrm{P}(\mathrm{Y})$ correlation function at GNSS L2 when using semi-codeless or codeless code tracking; $F_{\text {PRN }}$ is the sequence frequency of PRN pseudopulses (e.g., $F_{\mathrm{PRN}}=1.023 \cdot 10^{6}$ for the coarseacquisition (C/A) code and $10.23 \cdot 10^{6}$ for the encrypted $\mathrm{P}(\mathrm{Y})$ code).

Expressions (1) and (2) show the GNSS noise immunity during solar radio bursts depends on the following factors:

1) RF-chain characteristics (antenna pattern, antenna gain, thermal noise of the pre-amplifier, power losses in RF-chain elements, front-end bandwidth of the highfrequency chain);

2) tuning of the phase tracking loop, phase lock loop order, and Alan deviation of the reference oscillator;

3) range code characteristics (pseudopulse length and code length);

4) spectral characteristics of interference within the RF-chain bandwidth;

5) the encrypted signal processing algorithm at the second GNSS frequency as well as the phase tracking 
loop in channels of the second operating frequency (whether the L1-aiding technique is in use or not).

Thus, when observing the same bursts, solar radio emission impacts on GNSS receivers can differ greatly depending on the type and characteristics of a GNSS receiver, signal code (in the range code and in the carrier frequency), and system (GPS, GLONASS, etc.).

A failure in the phase tracking loop may lead to a sharp deterioration in the configuration of the navigation satellite constellation in view and to an increase in the positioning error. The mean error $\sigma$ in observation point positioning is related to the position of observable satellites through the position dilution of precision (PDOP) [Kaplan, 1996]:

$$
\sigma=\mathbf{D O P} \Delta \mathbf{R},
$$

where $\Delta \mathbf{R}$ is the mean range error for visible satellites; DOP is the position dilution of precision, which is determined by the satellite-receiver direction cosine matrix for the satellites in view.

At satellite signal losses of lock due to solar radio bursts or other heliogeomagnetic extreme events, of critical importance is the angular position of the "lost" satellite rather than the number of "lost" satellites. When the number of visible satellites is $\geq 4$, the satellite signal critical [Barabanova, 2010].

Since the beginning of the GNSS era, among the first and perhaps the most striking examples of GNSS performance deterioration caused by solar radio bursts are the events that occurred on December 6 and 13, 2006. On December 6, 2006, there was a powerful X6.5

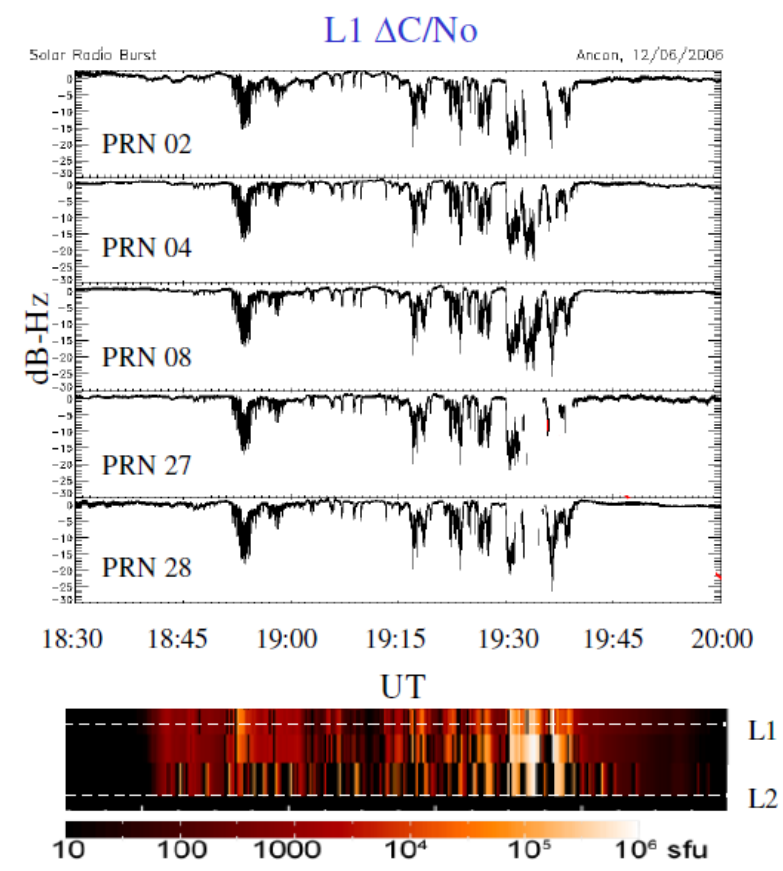

L1 2 loss of lock with the highest elevation angle is the most

\subsection{Experimental observations of the impact of radio bursts}

solar flare. This flare was not abnormally energetic in $\mathrm{X}$-ray (X) and extreme ultraviolet (EUV) ranges, but it was followed by a powerful radio burst. According to data from the radio spectrograph Owens Valley Solar Array (OVSA) [Cerruti et al., 2006, 2008], in the time span 19:30-19:40 UT the solar flux in the 1.2-1.6 GHz band exceeded $10^{5}$ s.f.u., at certain moments reaching $10^{6}$ s.f.u. (at a normal background level of $\leq 100$ s.f.u.), i.e. the power exceeded that of all radio bursts recorded since the beginning of the GNSS era at least by an order of magnitude. This extreme solar event caused massive failures in many broadband satellite radio systems, including GPS and GLONASS [Carrano et al., 2007; Afraimovich et al., 2009b; Demyanov et al., 2012a].

Figure 1 presents Ashtech Z-XII receiver data (the observation station Ancon, USA) showing a sharp decrease in the signal-to-noise ratio at the first and second GPS operating frequencies during the maximum of the December 6, 2006 radio burst [Carrano et al., 2007, 2009] . During the period of maximum radio emission power ( 19:32-19:38 UT), not only the sharp decrease in the signal-to-noise ratio, but also signal losses of lock occur for all the satellites considered at L2 and in some satellites at L1 (satellites 02, 04, 27, 28).

On the global scale, by simultaneously measuring ranging parameters, 1500 stations recorded a sharp increase in the relative density of failures in carrier phase tracking of GPS satellites $P(t)$ up to $18.5 \%$. This observation statistics applies to all visible satellites with low elevation angles (from $10^{\circ}$ to $40^{\circ}$ ) for solar radio bursts of $>100000$ s.f.u. The reference GPS receiver placed at the subsolar point simultaneously observed a sharp decrease in the signal-to-noise ratio from the normal level of 45 to $10 \mathrm{~dB}-\mathrm{Hz}$ (Figure 2) [Afraimovich et al., 2008;

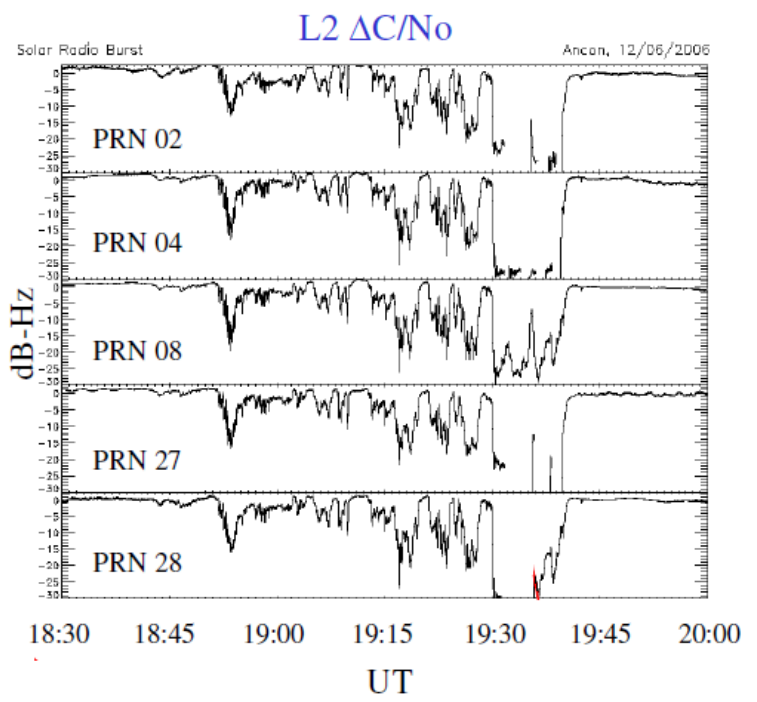

Figure 1. Dynamics of the signal-to-noise ratio for some GPS satellites at the operating frequencies L1 (left panel) and L2 (right panel) during the December 6, 2006 extreme solar radio burst. The bottom color scale shows radio flux power distribution from 18:30 to 20:00 UT. The figure has been taken from [Carrano et al., 2009] 
Afraimovich et al., 2009b]. There is nothing of this kind for the satellites of the same group on the reference day (see the signal-to-noise ratio indicated by the black line in Figure 2, $b$ ).

The solar radio bursts (Figure 2,e) correlate well with the sharp decreases in the signal-to-noise ratio (Figure 2,b) and with the increase in the relative density of count omissions $W(t)$ of all ranging parameters for the measurement period (Figure 2,c,d) for the satellites observed at approximately equal elevation angles. In particular, the density of count omissions $W(t)$ for the GPS satellite PRN 12 was as high as $82 \%$ (Figure 2,c). Maximum count omissions $W(t)$ are synchronous with the maximum solar flux (time marks T1, T2, and T3 in Figure $2, e$ ). Count omissions represent a more negative phenomenon than the noise gain in terms of positioning accuracy: absence of measurements of all ranging parameters in the current measurement epoch leads to a positioning failure. The radio burst impact was much less pronounced for satellites with elevation angles $>40^{\circ}$ (Figure 2, $a$, dashed line). This can be explained by a higher signal-to-noise ratio in the case of receiving signals from satellites with high elevation angles.

The spatial distribution of the intensity of L1 (L2) losses of lock is illustrated in Figure 3. It is apparent that during the radio emission maximum the dualfrequency measurement mode in GPS receivers was

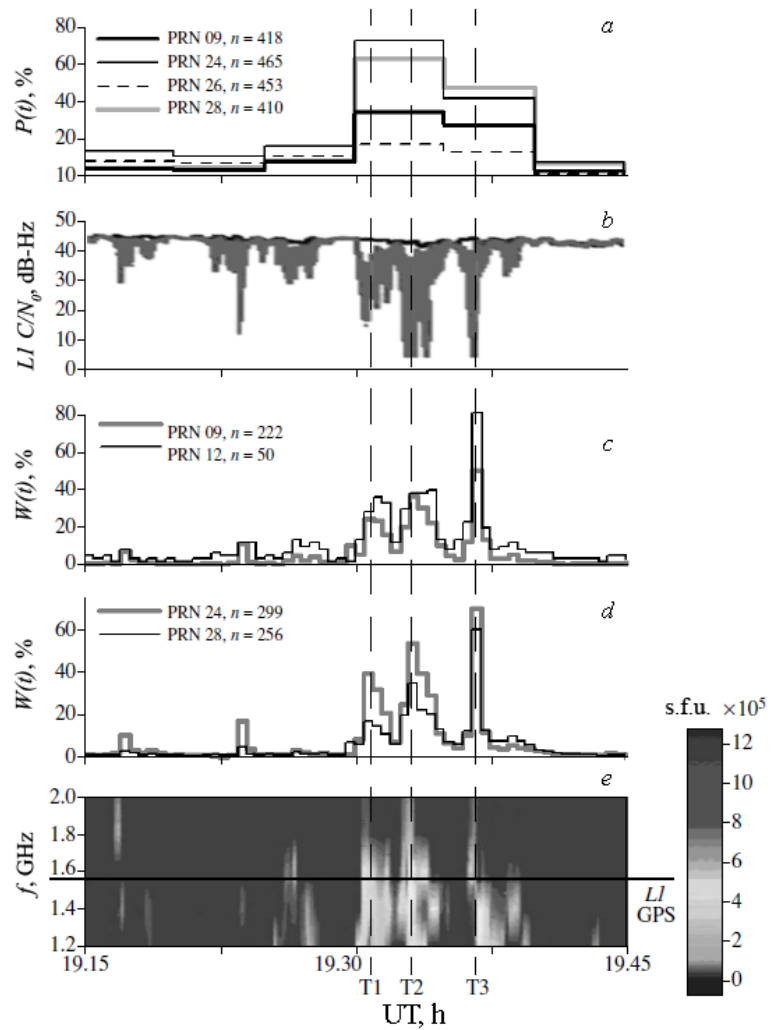

Figure 2. Ranging failures on December 6, 2006: $a, c, d-$ losses of lock $P(t)$ and count omissions $W(t)$ for different GPS satellites; $b$ - the signal-to-noise ratio at the first GPS frequency, recorded by a specialized GPS receiver; $e$ is the solar radio spectrum in the $1.2-2.0 \mathrm{GHz}$ band derived from OVSA data. The figure has been taken from [Afraimovich et al., 2009b]

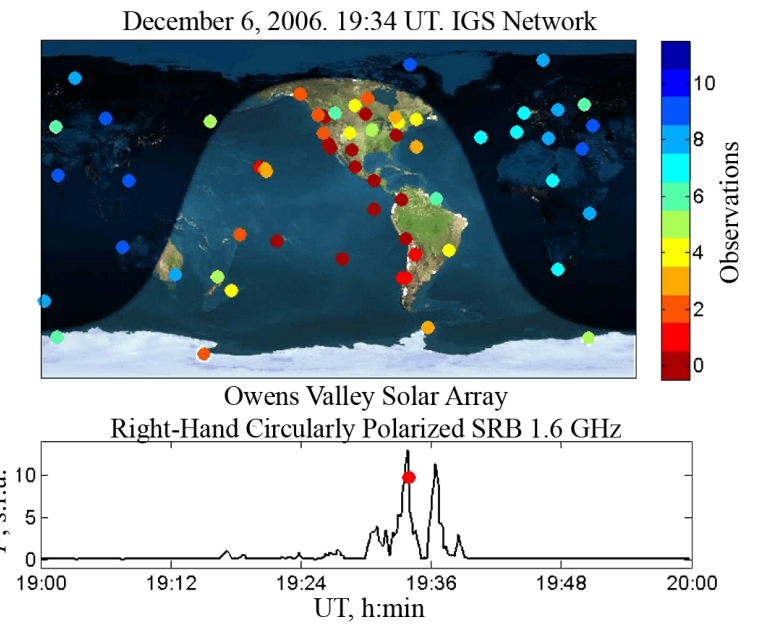

Figure 3. The number of visible satellites with available dualfrequency pseudorange measurements from IGS network data (top) and the radio emission dynamics (bottom) during the December 6, 2006 radio burst. The figure is adopted from [http: //gps.ece.cornell.edu/briefs.php]

unavailable virtually throughout the sunlit side of Earth (Figure 3, top panel; the moment 19:34 UT to which the image on the upper panel corresponds is marked with a red dot on the bottom panel).

An X-ray flare of a higher class is not necessarily accompanied by an equally powerful radio burst in the 1-2 GHz band. For example, the October 28, 2003 $\mathrm{X} 17.2$ burst occurred with a radio flux that did not exceed 6500 s.f.u. (Figure 4). The relative density of $W(t)$ was much lower than that on December 6, 2006, and is omitted here. While the level of the October 28, 2003 radio burst was by two orders of magnitude lower than the December 6, 2006 extreme one, the relative density of losses of lock at L2 was three times higher than the background level, running to $P_{\max }=1.66 \%$ in processing of measurements from all satellite in view.

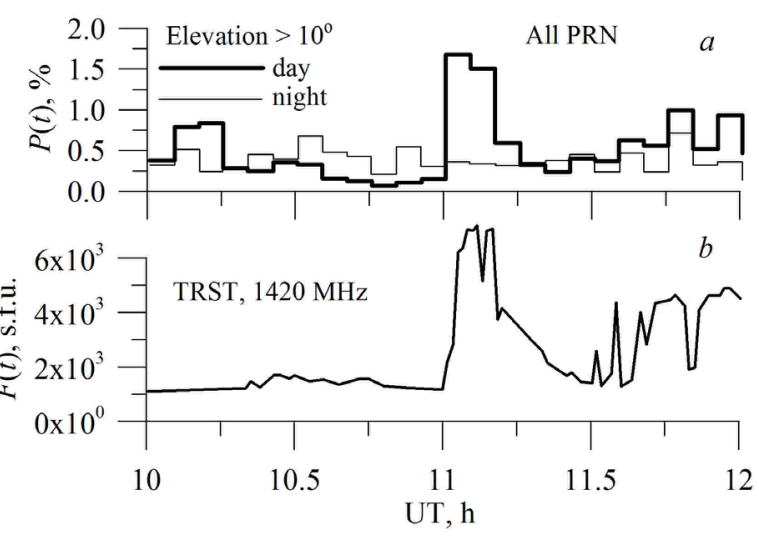

Figure 4. Relative density of losses of lock $P(t)(a)$ caused by the October 28, 2003 solar radio burst for all GPS satellites on the sunlit side of Earth and the solar radio flux $(b)$ according to TRST data at $1420 \mathrm{MHz}$. The top panel: the thick line indicates the dependence of the loss-of-lock intensity $P(t)$ for the dayside, obtained for $n=2452$ of satellite-receiver lines of sight at elevation angles $\theta>10^{\circ}$; the thin line shows the same data for the nightside. The figure has been taken from [Afraimovich et al., 2009b] 
The shape of the curve of dayside phase losses of lock agrees with the shape of the envelope of the radio flux recorded by RSTN's radio spectrograph TRST in Trieste [https://www.ngdc.noaa.gov/stp/space- weather/solardata/solar-features/solar-radio/rstn-1-second/]. Relative density of losses of lock on the nightside of Earth (thin line) did not exceed the background level.

The main cause of GNSS and WAAS performance deterioration during solar radio bursts being a sharp decrease in the equivalent signal-to-noise ratio at the input of the tracking loop, the satellite signal strength increase should reduce the damage from such events. According to the GPS interface control document [https://gps.gov/ technical/icwg/IS-GPS-200J.pdf], in new satellites, beginning with the IIR-M unit, the transmitted signal power has been increased. The radio bursts on September 24, 2011 [Sreeja et al., 2013] and September 6, 2017 [Berdermann et al., 2018; Yasyukevich et al., 2018], classified [Huang et al., 2018] as extreme and severe respectively, offer an opportunity to compare burst effects on old and new satellites.

Figure 5 shows the dynamics of received satellite signal power for different signal codes (gray, blue, and black curves) and the dynamics of solar radio emission power during the aforesaid radio bursts (red curve). Measurements of the signal strengths S1C (coarse acquisition code, L1 frequency) and $S 2 W$ (encrypted signal code, L2 frequency) were recorded for both old (IIA/IIR-A) and new (IIR-M/IIF) orbital GPS units. These $S 2 X$ signal strengths observed (civilian signal code, L2 frequency) allow us to evaluate advantages of
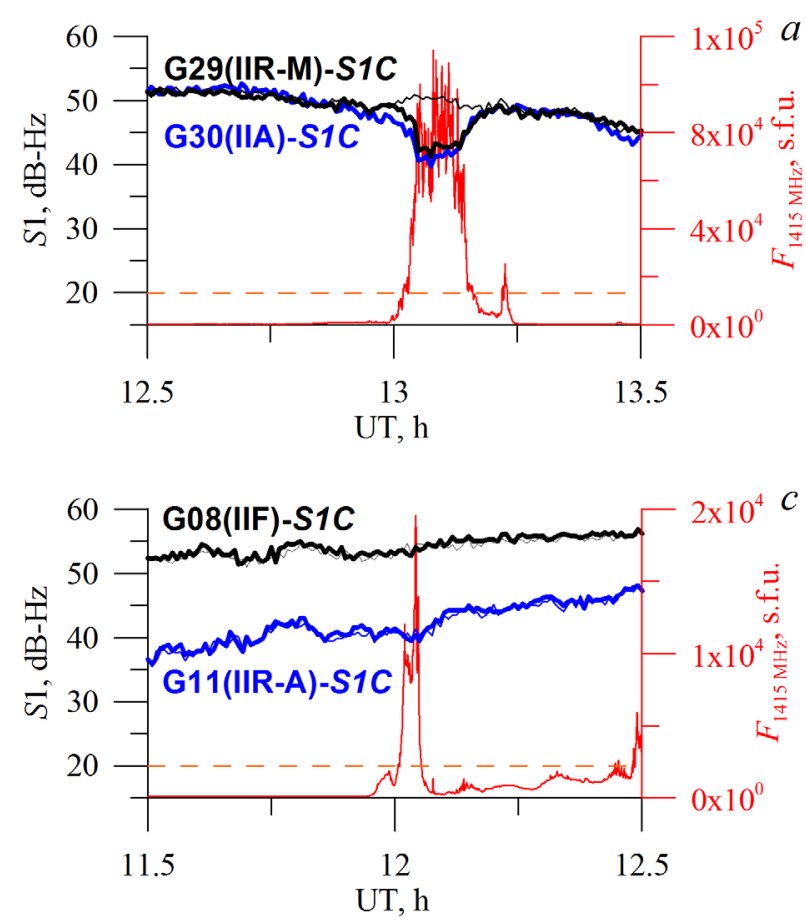

using new civilian signal codes (L2C). As a signal strength threshold, which determines the potential GNSS noise immunity, a value of $20 \mathrm{~dB}-\mathrm{Hz}$ is taken [Psiaki, 2001]. In the figure, this threshold is marked with orange dashed lines.

Figure 5 indicates that solar radio bursts are followed by a decrease in the received signal strength - to a lesser extent at the L1 frequency and to a far greater extent at the L2 frequency. During the maximum of the September 24, 2011 extreme burst, the strength of the L2 received signal from the IIA unit falls below $20 \mathrm{~dB}-\mathrm{Hz}$, whereas for the IIR-M unit minimum values are higher by $\sim 5 \mathrm{~dB}$ $\mathrm{Hz}$ (Figure 5, b). When using the L2 civilian signal code (observable $S 2 X$ ), the reduction in the signal strength is much lower (the gain is $\sim 15-20 \mathrm{~dB}-\mathrm{Hz}$ ) and is comparable with the similar fading in the signal strength of the L1 civilian code (Figure 5,a). For new orbital units IIF with higher signal strength, the radio burst in 2017 exerted no effect on the L1 signal (Figure 5,c), slightly affecting the L2 signal (Figure 5,d). In the latter case, the use of the $\mathrm{C} / \mathrm{A}$ code at L2 even further reduces the time and decreases the signal strength fading during the peak of the radio burst.

What is important from a practical point of view is the final positioning accuracy of GNSS users under severe radio bursts. Figure 6 presents data on the positioning accuracy during three radio bursts that occurred in 2002-2011. We solved the navigation problem in dualfrequency modes of standard point positioning (SPP) [Hofmann-Wellenhof et al., 2001] $(a, c, e)$ and precise
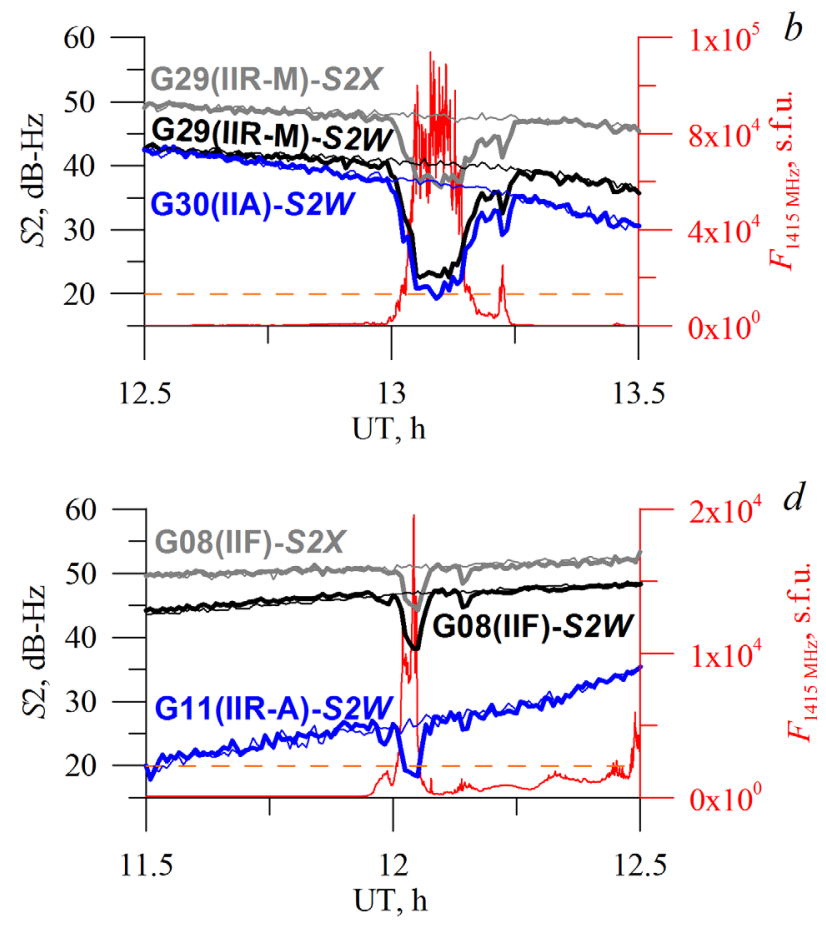

Figure 5. Dynamics of solar radio emission at a frequency of $1415 \mathrm{MHz}$ (red curves) and received GPS signal strength (black, blue, and gray curves) at L1 (left panels) and L2 (right panels) during the solar radio bursts on September 24, $2011(a, b)$ September 6, $2017(c, d)$ : blue thick curves are $S 1 C$ and $S 2 W$ signal strengths for the IIA/IIR-A satellites; black thick curves, $S 1 C$ and $S 2 W$ signal strengths for IIR-M/IIF; the thick gray curve, $S 2 X$ signal strength for IIR-M/IIF; thin lines are strengths of respective signals on September 23, 2011 and September 5, 2017 (before the bursts). The data has been acquired by the reference receiver at the station ZIM2 (USA). The radio flux has been recorded by the Sagamore Hill radio spectrograph of RSTN. The figures is adopted from [Yasyukevich et al., 2021] 
point positioning (PPP, Figure $6, b, d, f$ ) [Zumberge et al., 1997]. Positioning errors in the SPP mode were calculated using the software Navi [Zatolokin, 2020]. Calculations in the PPP mode were carried out with the software GAMP [Zhou et al., 2018].

Figure 6 also provides insight into the results of modernization of the system by improving satellite equipment. Observations in 2002 show a fairly high background level of range error - up to 10-15 m. However, even at such large background errors we can see a four-five-fold positioning accuracy deterioration due to the solar radio burst impact. Later observations in 2006 demonstrate a significantly lower background level of range errors $(2-8 \mathrm{~m})$. In this case, a solar radio burst led to a two-three-fold positioning accuracy deterioration as compared to the observations on the reference day. Observations in 2011 also show a fairly low back-

Standard dual-frequency mode ground level of range error (less than $6.5 \mathrm{~m}$ ). During the radio burst, the positioning accuracy decreases 8-10 times relative to the reference day; this effect is pronounced and correlates well with the solar radio flux dynamics.

Thus, despite GNSS having been improved, the problem of the impact of solar radio bursts on the final positioning accuracy is still unresolved.

The positioning accuracy in the kinematic PPP mode is normally tens of centimeters (Figure $6, b, d$, $f)$. The increasing positioning error correlates well with the radio burst intensity. During peaks of the radio bursts, the positioning accuracy in the PPP mode deteriorated to a few meters. In 2011, the data presented shows that the PPP mode failed, while the standard dual-frequency mode kept operating normally, albeit with lower accuracy. During the September 6, 2017

\section{PPP}

April 21, 2002
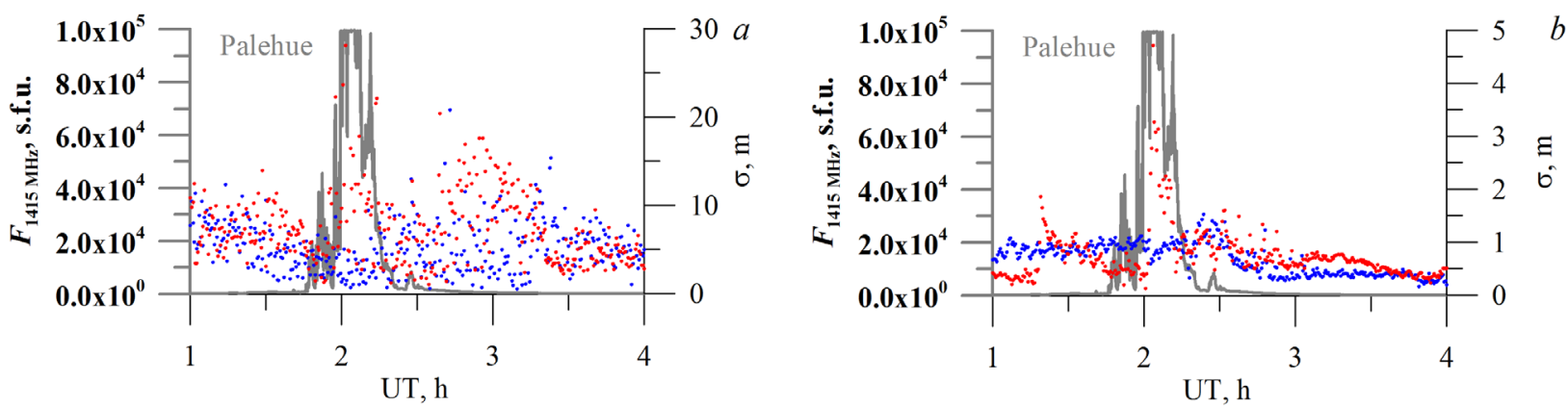

December 6, 2006
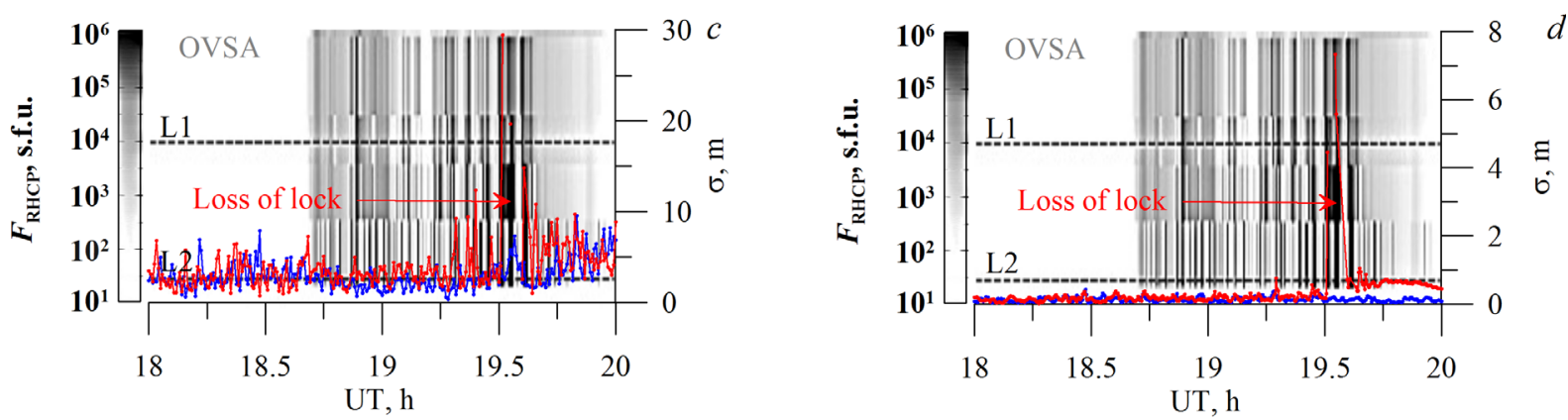

September 24, 2011
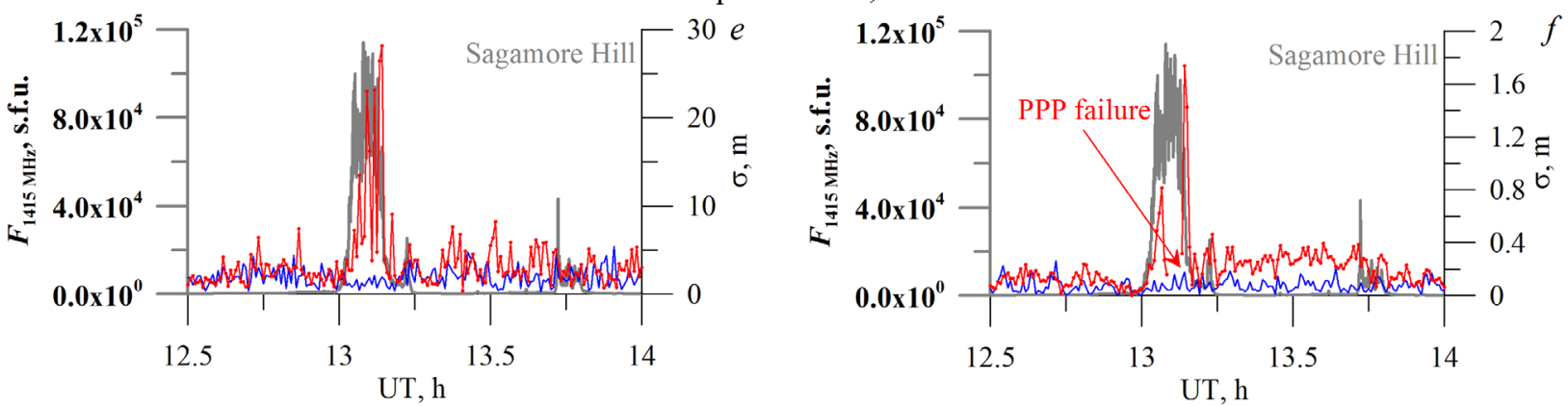

Figure 6. GNSS performance deterioration in the dual-frequency SPP $(a, c, e)$ and PPP $(b, d, f)$ modes under the solar radio bursts that occurred on April 21, $2002(a, b)$, December 6, $2006(c, d)$, and September 24, $2011(e, f)$ : the red curve shows the days of the bursts; the blue curve, the reference day. The gray color indicates the emission flux at a frequency of 1415 $\mathrm{MHz}$ (left scale) and names of radio spectrographs; the right scale is a positioning error. GNSS stations located at the subsolar point with the highest solar zenith angle: MAUI (2002), BUEN (2006), and BJCO (2011) 
solar radio burst (a maximum power of 19604 s.f.u. ), the mean positioning error in the dual-frequency PPP mode increased from $0.2 \mathrm{~m}$ for GPS and $0.5 \mathrm{~m}$ for GLONASS to $\sim 0.6 \mathrm{~m}$ [Yasyukevich et al., 2018].

Along with the impact of solar radio emission, of particular significance may be the effect of an abrupt change in the total electron content (TEC) of the ionosphere [Rodríguez-Bilbao et al., 2015] due to the formation of small-scale irregularities and the attendant navigation signal scattering. It should be noted that the single-frequency PPP mode is more resistant to negative factors of increased radio emission than the dualfrequency PPP mode [Berdermann et al., 2018]. Under extreme conditions, at a higher probability of the L2 signal loss of lock, the single-frequency PPP mode may provide higher reliability and positioning accuracy. Most of the time, the dual-frequency PPP mode is more accurate than the single-frequency one, which results in the preferential use of dual-frequency receivers.

\section{IMPACT OF GEOMAGNETIC DISTURBANCES ON GNSS PERFORMANCE}

\subsection{Background on the mechanism and na- ture of the impact}

The key role in generating geomagnetic disturbances is played by coronal mass ejections (CME) and highspeed solar wind streams, linked to corotating interaction regions (CIR) on the Sun. The most probable drivers of geomagnetic storms are magnetic clouds associated with CMEs [Yermolaev et al., 2013]. CMEs are accompanied by emission of accelerated charged particles (electrons and protons). If the flux propagation axis is earthward, the most energetic particles (with an energy of $10^{8}-10^{9} \mathrm{eV}$ ) arrive at Earth $\sim 10 \mathrm{~min}$ after CME maximum. This particle flux, observed sometimes for several tens of hours [Bruzek, Durrant, 1977], is responsible for the amplification of electric currents in near-Earth space (electrojet), auroral emissions of charged particles and, as a secondary effect, the generation of small-scale ionospheric electron density irregularities in the auroral zone.

Another consequence of CME and CIR is the generation of a strong shock wave propagating in interplanetary space. Given a typical speed of $\sim 500 \mathrm{~km} / \mathrm{s}$, this shock wave [Gulyaeva, Gulyaev, 2020] reaches Earth within 3-4 days (for ultraspeed CMEs with a speed of $2500 \mathrm{~km} / \mathrm{s}$, within $\sim 12 \mathrm{hr}$ ) and leads to magnetosphere compression. When interplanetary magnetic field (IMF) is southward, IMF lines reconnect with geomagnetic field lines, solar energetic particles are trapped. This results in an enhancement of the electrojet whose counter magnetic field causes a sharp decrease in the $H$ component of the geomagnetic field, which lasts from a few hours to days (the geomagnetic storm main phase) [Akasofu, Chapman, 1972].

Most magnetospheric processes manifest themselves in significant variations of ionospheric and plasmaspheric parameters [Bazarzhapov et al., 1979], in particular during the main phases of global geomagnetic storms. Weaker and frequent disturbances - substorms - driven by the same processes occur in the polar magnetosphere [Bazarzhapov et al., 1979]. Storm- and substorm-induced irregular electron density and TEC variations in the ionosphere and plasmasphere with local and global distributions last from several minutes to several days [Afraimovich, Perevalova, 2006].

Effects of geomagnetic storms generally show up at high and low latitudes. At high latitudes, geomagnetic storm effects are associated with energetic particle precipitation, additional ionization, and formation of smallscale irregularities, which cause signal scattering; at low latitudes, with ring current amplification and development of plasma instabilities in the ionosphere. The expansion of the auroral oval to midlatitudes gives rise to significant effects of storms in these regions [Afraimovich, Perevalova, 2006].

Effects of radio wave propagation through the nonuniform and nonstationary ionosphere and the plasmasphere, except for interference fading and scintillation of signal amplitude and phase (which depend on characteristics and pattern of local electron density distribution) are directly related to the TEC value along the propagation path and to the rate of its change [Yakovlev, 1998]. Among these effects are phase and group delays, including refractive fluctuations, as well as regular and irregular variations of GNSS signal in its passage through the ionosphere (refractive attenuation and polarization fading due to the Faraday effect) [Hargreaves, 1979].

Refraction increment of the group (phase) path in the ionosphere depends on the distribution of the refractive index along the signal path:

$$
d R= \pm \frac{40.4}{f^{2}} \int_{S} N(s) d s= \pm \frac{40.4}{f^{2}} I,
$$

where $N(s)$ is the electron density distribution function along the signal path; $f$ is the carrier frequency of the signal, Hz; $I=I_{0}+d I$ is TEC along the satellite-receiver line of sight; $I_{0}$ is the regular part of TEC along the satellite-receiver line of sight; $d I$ is the TEC fluctuation component caused by variations in $N(s)$ along the satellite-receiver line of sight.

Moreover, the signal strength at the input of the code and phase tracking loop is related to standard deviations of phase and code pseudodelay errors by the signal-tonoise ratio. Variations in the satellite navigation signal strength at the output from an inhomogeneous nonstationary ionospheric layer (due to polarization fading and refraction attenuation) will increase GNSS ranging errors during geomagnetic disturbances.

The above refraction effects are significant for GNSS signal positioning in the single-frequency mode, as well as for differential navigation, whose efficiency is limited by space-time TEC gradients within the coverage area of this system [Warnant et al., 2007]. Nonetheless, the most significant negative effects of geomagnetic variations and storms are ionospheric scintillations. In Section 3, we separately analyze the mechanism of the ionospheric scintillation impact on the quality of GNSS performance, using the standard dualfrequency mode and solving precision positioning problems (PPP, RTK modes). 


\subsection{Experimental observations of the im- pact of geomagnetic disturbances}

First experiments have shown that the quality of GPS performance during magnetic storms deteriorates [Coster et al., 2001; Afraimovich et al., 2002]. The number of signal losses of lock increased generally during the magnetic storm main phase when the geomagnetic disturbance was maximum (Figure 7). The number of ranging failures for some satellites correlates with the geomagnetic storm intensity [Astafyeva et al., 2014]. Loss of signals from even one navigation satellite may cause a sharp increase in the position delusion of precision and hence in the positioning error [Demyanov, Yasyukevich, 2014].

The strongest effects of magnetic storms occur in the auroral oval [Astafyeva et al., 2014]. In this very region, the greatest geomagnetic field and TEC variations are observed [Kozyreva et al., 2017]. Figure 8 indicates that at high latitudes there are maximum positioning errors and the maximum number of losses of lock.

At some monitoring stations at midlatitudes, the GPS positioning error in the PPP mode may increase five times relative to the background level and reach $0.5 \mathrm{~m}$ [Yasyukevich et al., 2020b] (Figure 8), although for most storms it does not exceed $0.3 \mathrm{~m}$ [Luo et al., 2018].

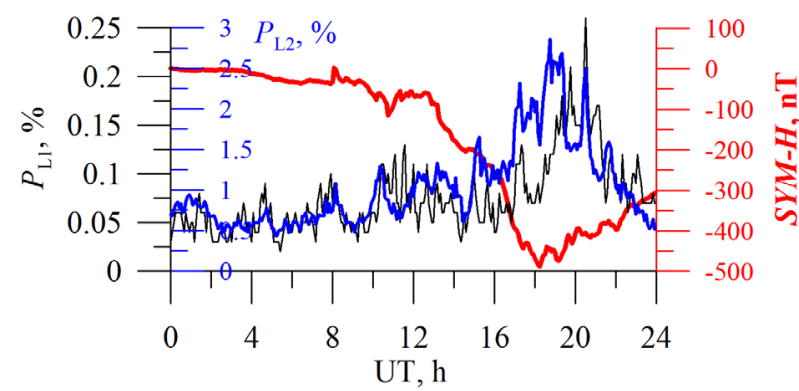

Figure 7. Dynamics of losses of lock during the main phase of the November 20, 2003 magnetic storm according to data from the global network of receivers: the red line is the geomagnetic activity index $S Y M-H$ (right scale); black and blue curves show the relative number of losses of lock at L1 and L2 respectively (left scales). The data has been taken from Figure 3 in [Astafyeva et al., 2014]

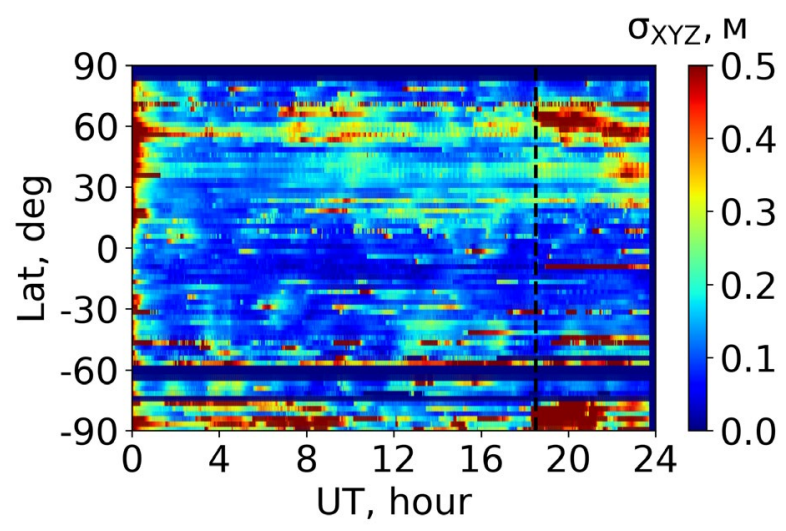

Figure 8. Latitude and time dependence of PPP errors in the American sector on June 22, 2015 (Figure 5, b from [Yasyukevich et al., 2020b])
Optical data confirms that GNSS signal losses of lock are associated with auroral particle precipitation in the high-latitude ionosphere [Zakharov et al., 2020]. It has also been found that upon expansion of the auroral oval to midlatitudes the region of increased positioning errors in different modes shifts in the same direction [Demyanov, Yasyukevich, 2014; Afraimovich et al., 2009a; Yasyukevich et al., 2020b].

\section{NAVIGATION SATELLITE SIGNAL AMPLITUDE AND PHASE SCINTILLATIONS AND THEIR IMPACT ON GNSS RECEIVER PERFORMANCE}

\subsection{Physical mechanisms of the impact}

The main cause of strong signal amplitude and phase scintillations is signal scattering by small-scale electron density irregularities with sizes of the order of the first Fresnel zone radius ( $r=\sqrt{\lambda z} z$ is the effective distance to a layer with irregularities; $\lambda$ is the wavelength) [Kravtsov, 1983]. For GNSS, the first Fresnel zone is 100$300 \mathrm{~m}$. Scattering by large-scale irregularities (units and tens of kilometers) is largely manifested in scintillations and short-term phase variations [Bhattacharrya et al., 1992].

A quantitative measure of the amplitude and phase scintillation intensity is generally the scintillation indices $S_{4}$ and $\sigma \varphi$ respectively. Under weak scintillations $\left(S_{4} \leq 0.3-0.4\right.$ and $\left.\sigma \varphi \leq 0.1-0.2\right)$, there is a linear relationship between $S_{4}, \sigma \varphi$ and the intensity of electron density irregularities [Rino, 2011]. Since the intensity of the irregularities affects radio signal parameters, the scintillation indices can be used for predicting operational stability of radio systems exploiting a transionospheric radio wave propagation channel [Pashintsev, Akhmadeev, 2015].

When a signal propagates in a thick layer of scattering irregularities, strong amplitude scintillations occur due to the diffraction effect (scattering and multiple interference of diffracted waves). Strong phase scintillations in this case result mainly from refractive beam jitter when passing through a layer with small-scale electron density irregularities [Kolesnik et al., 2002]. Thus, in the case of multiple scattering strong ionospheric amplitude and phase scintillations have a different origin and hence a different character of amplitude and phase scintillation spectra [McCaffrey, Jayachandran, 2017], and feature a different response of the scintillation indices $S_{4}$ and $\sigma \varphi$.

Small-scale electron density irregularities are nearly always observed in the high-latitude and equatorial (dusknightside) ionosphere [Aarons, 1982]. The reason for this is that in auroral zones and at equatorial latitudes in the ionosphere the mechanisms for generation of irregularities with the scales considered work steadily - two-stream and gradient-drift instabilities [Akasofu, Chapman, 1972]. In this case, the condition of the occurrence of small-scale irregularities is fulfilled - strong ion-electron drift velocities of the order of or higher than the ion sound velocity. 
A change in the geomagnetic disturbance level reflects on the amplitude scale of the irregularity spectrum [Afraimovich, Perevalova, 2006]: the amplitude of electron density irregularities of the entire range of scales increases proportionally - from meter to kilometer and larger.

The conditions needed to generate small-scale electron density irregularities may occur in the mid-latitude ionosphere during severe geomagnetic disturbances [Afraimovich et al., 2009a] and during the formation of sporadic layers that feature steep ionospheric gradients [Pashintsev, Gamov, 2002]. The region of small-scale irregularity intensification at midlatitudes is most often associated just with auroral activity and has the form of a multiscale ionospheric disturbance that follows the uniformly moving or pulsating southern boundary of the auroral oval. The length of the front edge of this region may be thousands of kilometers; the depth, hundreds of kilometers. During the geomagnetic disturbance main phase, the pulsating auroral oval boundary may also produce a large-scale acoustic-gravity wave (AGW), which propagating to midlatitudes "pulls" the region of high ionospheric gradients generating small-scale electron density perturbations.

Another mechanism behind the intense small-scale irregularities at midlatitudes is penetration of such specific ionospheric irregularities as equatorial plasma bubbles into this region [Ma, Maruyama, 2006]. Transverse dimensions of the bubbles are largely in the range 115-460 km [Smith, Heelis, 2017], the electron density within the bubble is lower by $15-20 \%$ relative to the background. The bubbles are generally concentrated within $\pm 20^{\circ}$ relative to the geomagnetic equator [Huang et al., 2011], but there is evidence for their penetration into midlatitudes up to $\sim 34-38^{\circ} \mathrm{N}$ [Ma, Maruyama, 2006; Demyanov et al., 2012b; Cherniak, Zakharenkova, 2016; Aa et al., 2018].

Ionospheric plasma instability on the walls of the bubble related to the electron density gradients leads to the generation of small-scale irregularities directly responsible for the occurrence of strong ionospheric radio signal scintillations. The highest intensity of the scintillations occurs in the magnetic zenith, i.e. when the beam trajectory goes along the geomagnetic field line [Anderson, Straus, 2005] and hence across the length of the bubble. The standard deviations of phase $\sigma \varphi[\mathrm{rad}]$ and pseudorange $\sigma R[\mathrm{~m}]$ are related to the scintillation level as follows [Kaplan, 1996; Conker et al., 2003]:

$$
\begin{aligned}
& \sigma R=L \times \\
& \times \sqrt{\frac{4 F_{1} d^{2} \Delta F_{\mathrm{DLL}}}{10^{0.1 C N_{0}}}\left(2(1-d)+\frac{4 F_{2} d}{T_{\mathrm{COR}} \cdot 10^{0.1 C N_{0}}}\right)}, \\
& \sigma \varphi=\left(160 \frac{\sigma_{f} f}{\Delta F_{\mathrm{PLL}}}\right)^{2}+\left(\frac{360}{2 \pi}\right)^{2} \times \\
& \times \frac{\Delta F_{\mathrm{PLL}}\left(1+\left[2 T_{\mathrm{COR}} \cdot 10^{0.1 C N_{0}}\left(1-S_{4}{ }^{2}\right)\right]^{-1}\right)}{10^{0.1 C N_{0}}\left(1-S_{4}{ }^{2}\right)},
\end{aligned}
$$

where $L=c / L_{\text {cod }}$ is the wavelength of PRN cod ; $c$ is the velocity of light; $L_{\text {cod }}$ is the range code length, pulse/s;
$F_{1}, F_{2}$ are parameters depending on the type of correlator and discriminator of delay tracking loop (typical values: $\left.F_{1}=0.5, F_{2}=1\right) ; d$ is the code delay correlator spacing in parts of the code chip length (typical values $\left.d=(0.1 \div 0.5) t_{\text {pulse }}\right) ; \Delta F_{\text {DLL }}, \Delta F_{\text {PLL }}$ is the noise bandwidth of the tracking loop for pseudodelay and pseudophase respectively; $C N_{0}$ is the signal-to-noise ratio at the input of the phase and pseudodelay tracking loop, $\mathrm{dB} W ; T_{\mathrm{COR}}$ is the measurement averaging time in the correlator, $\mu \mathrm{s}$; $\sigma_{f}$ is the short-term frequency instability of the reference oscillator; $f$ is the signal carrier frequency, $\mathrm{Hz}$.

Figure 9 depicts the relationship between standard deviations of estimated phase and pseudorange for a fixed signal-to-noise level of $40 \mathrm{~dB}$ at the input of the L1 C/A tracking loop at different amplitude scintillation levels $\left(S_{4}\right)$. The amplitude scintillations cause a weak linear increase in phase error up to the scintillation level $S_{4} \sim 0.7$, but at a higher level a sharp nonlinear increase in the error begins. The pseudorange error also increases approximately linearly in the region of weak scintillations $\left(S_{4}<0.4\right)$, but faster than the phase error.

In the region of strong scintillations, the range error begins to increase nonlinearly, but its rise is much smaller than that of the phase error at the same scintillation intensity.

It is known that the phase tracking loop can operate if the condition $\sigma \varphi \leq 15^{\circ}$ is met [Kaplan, 1996]. However, as scintillations intensify the minimum signal-tonoise ratio value at the input of the phase-tracking loop, required to maintain stability of the phase filtering, increases. During weak and moderate scintillations with $S_{4} \leq 0.4-0.5$, the threshold of the minimum signal-to-noise ratio increases at most by $2-3 \mathrm{~dB}$ W, and during more intense scintillations its increase is already significant: at $S_{4}>0.6$, e.g., $10-12 \mathrm{~dB}$ W [Demyanov, Yasyukevich, 2014].

To achieve the best measurement accuracy, pseudodelay is filtered in a coherent mode, therefore the stability of ranging parameter measurements depends on the stability of the phase lock loop. A phase loss of lock entails drastic code delay accuracy deterioration or signal loss of lock of a navigation satellite as a whole. Formulas (4) and (5) indicate that phase tracking loop settings have a significant effect on the carrier phase tracking stability. Accordingly, adaptive tracking loop tuning may be one of the effective ways for improving the GNSS receiver stability under ionospheric scintillations.
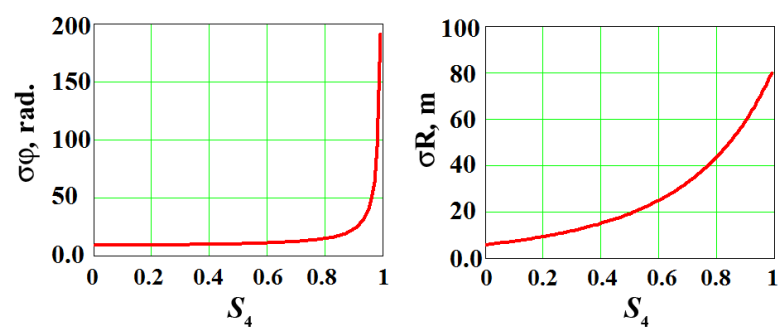

Figure 9. Effect of amplitude scintillations on phase (left) and pseudorange (right) accuracy 


\subsection{Experimental observations of the impact of amplitude scintillations}

Vadakke et al. [2020] have experimentally shown that the error in the phase lock loops may increase 5-10 times during scintillations. In this case, the scintillation intensity and the phase error differ significantly for signals from different satellites received by one station. This is due to the localization of irregularities and the magnetic zenith effect in observing electron density bubbles. For example, during the occurrence of the equatorial bubble at midlatitudes it was precisely these satellites located in the vicinity of the magnetic zenith that had the highest probabilities of phase losses of lock [Demyanov et al., 2012b].

Positioning accuracy in the standard mode also decreases when exposed to scintillation effects. Linty et al. [2018] have shown that scintillations may at least double the positioning error. In this case, errors are grouped into two disjoint clusters: the first corresponds to quiet conditions; the second, to the presence of scintillations. This allows us to develop algorithms for detecting these adverse events.

The positioning error in the PPP mode due to the impact of scintillations caused by equatorial bubbles may be as great as several meters [Moreno et al., 2011]. Figure 10 gives an example of the close correlation between the 3D positioning error and the scintillation in$\operatorname{dex} S_{4}$ in the low-latitude ionosphere. In observations in the high-latitude ionosphere, the effect of positioning accuracy deterioration caused by the ionospheric scintillation impact may be even more dramatic than at low latitudes due to the poorer geometry of the constellation of navigation satellites at high latitudes and, accordingly, higher DOP values [Dabove et al., 2020].

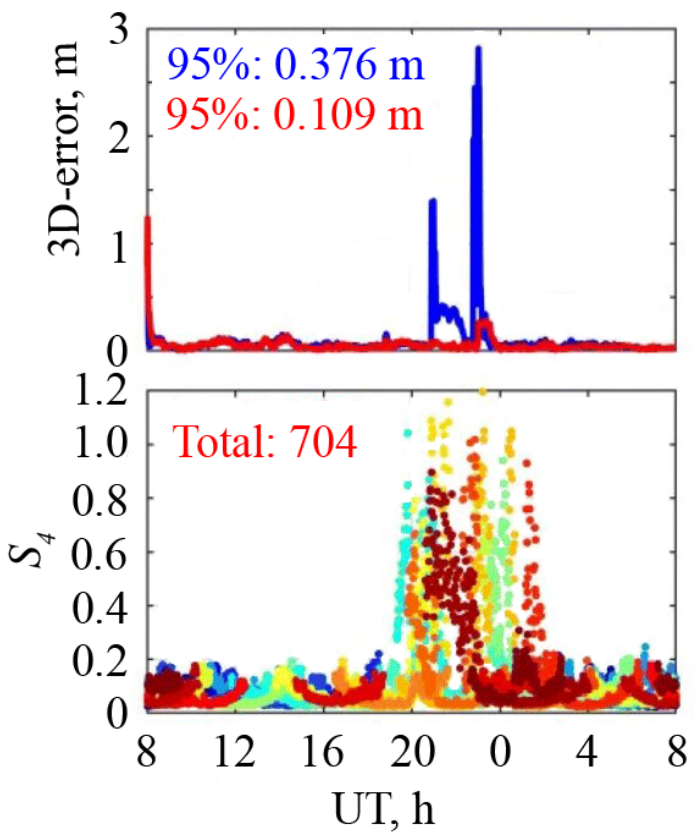

Figure 10. Amplitude scintillation index $S_{4}$ at the GPS L1 frequency (bottom) and a 3D positioning error in the PPP mode (top), in the standard mode (blue curve) and with correction by the method of dynamic statistical weights (red curve). Data for the Hong Kong station, October 19, 2015. Part of the figure is from [Luo et al., 2020]
The main reasons for the PPP deterioration under ionospheric scintillations are signal losses of lock for individual satellites due to increasing position dilution of precision, abnormal range errors as part of the navigation function, failures in cycle slip detection algorithms [Zhang et al., 2014]. Nonetheless, as demonstrated above (Figure 10), rejection of measurements from some satellites, which contain the abnormal errors, and improvement of receiver autonomous integrity monitoring (RAIM) significantly increase the reliability and accuracy of positioning determination [Zhang et al., 2014; Vani et al., 2019].

\section{GNSS PERFORMANCE IN DIFFERENTIAL MODE DURING SPACE WEATHER EVENTS}

\subsection{Physical mechanisms of the impact}

There are three basic types of GNSS integrity differential correction and monitoring systems: Satellite Based Augmentation Systems (SBAS), Local Based Augmentation Systems (LBAS), and Ground-Based Regional Augmentation Systems (GRAS). The most widely used among them are ground-based/space-born Wide-Area Augmentation Systems (WAAS, EGNOS, etc.) and Local Based Augmentation Systems for Real Time Kinematic (RTK).

The impact of extreme space weather events on GNSS users in the differential navigation mode is indirect - through the quality of differential corrections and accuracy of required navigation parameter (RNP) availability alerts. Differential corrections to range errors of GNSS satellites are formed by decomposing real range errors estimated from signals of the same satellites at the network of WAAS reference stations at a time $t_{0}$. With only rapid corrections (sensitive to extreme heliogeophysical events), pseudoranges at a current time point $t_{i}$ relative to the reference time $t_{0}$ are corrected in a GNSS receiver as follows [GPS-WAASPS, 2008]:

$$
\begin{aligned}
& P R_{i, \mathrm{COR}}=P R_{i, \mathrm{REAL}}+F C_{i}+ \\
& +R R C_{i}\left(t_{0}-t_{i}\right)+I C_{i}+T C_{i},
\end{aligned}
$$

where $P R_{i}$, COR, and $P R_{i}$, REAL are corrected and real pseudoranges; $F C_{i}$ are «rapid» corrections to errors caused by short-term instability of the on-board reference time and satellite frequency and selective availability (if enabled); $R R C_{i}$ is the range rate correction; $I C_{i}$ is the ionospheric range error correction; $T C_{i}$ is the tropospheric range error correction.

In Formula (6), the ionospheric error $I C_{i}$ is estimated from processed slant ionospheric error measurements performed at WAAS reference stations by a dualfrequency measurement method [Hofmann-Wellenhof et al., 2001]. RNP availability alerts are formed on the basis of estimates of their Protection Levels (PL) in the horizontal (HPL) and vertical (VPL) planes: the current PL estimate should not exceed the maximum positioning error in each plane. If the contrary is observed in a GNSS receiver, the user positioning at a given RNP level is considered unavailable, as the system issues an alert to all users in the coverage area. 
In general, the RNP protection level $P L$ is calculated based on the current geometry of navigation satellite constellation (with respect to a user) and the variance of residual range errors corresponding to these satellites after applying differential correction (6) [GPS-WAASPS, 2008]:

$$
P L=k D_{M J R},
$$

where $k$ is the confidence coefficient for the acceptable positioning error range in a given plane; $D_{M J R}$ is the trace of matrix containing combined observations of the satellite constellation geometry and their associated range errors.

As follows from Formula (7), under adverse heliogeophysical conditions the WAAS deterioration in issuing RNP boundary integrity alerts may be caused by three factors:

1. Unavailability or sharp deterioration in the accuracy of correction to ionospheric error (6), which increases the variance of the residual range error included in the estimate of $D_{M J R}$.

2. Navigation satellite signal jamming by solar radio flux, which entails a decrease in the signal-to-noise ratio and a corresponding increase in variance of pseudorange measurements $P R_{i, \text { REAL }}(6)$ included in $D_{\text {MJR }}$.

3. Signal loss of lock of a part of visible satellites under solar radio emission or small-scale disturbances within the WAAS coverage area, which leads to an increase in the position delusion of precision (and, accordingly, to corresponding changes in the estimate of $D_{M J R}$ ).

These phenomena may result in an increased probability of a false alert or dangerous mismatch in creating an RNP boundary violation alert within the WAAS coverage area [Demyanov et al., 2019].

The first two factors also apply to the Local Based Augmentation Systems for Real Time Kinematic (RTK). In addition, the LBAS efficiency is limited by space-time TEC gradients within the coverage area of this system [Warnant et al., 2007; Jacobsen, Schäfer, 2012].

\subsection{Experimental observations}

During extreme solar radio bursts, serious failures in WAAS performance may occur in terms of the availability of required navigation parameters within the coverage area. For example, when issuing RNP unavailability alerts according to the requirements of air navigation LPV200 (requirements for landing with vertical guidance to a landing decision point height of 200 feet), a significant reduction has been found in the RNP availability area [Carrano et al., 2007]. Figure 11 shows an about twofold decrease in the WAAS coverage area, within which RNP were available according to the LPV200 requirements during the December 6, 2006 extreme solar radio burst. The figure shows a pattern on December 6, 2006 according to data from the Air Navigation Service/the United States Federal Aviation Administration

[https://www.nstb.tc.faa.gov/DisplayArchive.htm].

As mentioned above, LBAS are very susceptible to adverse effects of ionospheric disturbances triggered by a magnetic storm. Under quiet conditions, ionospheric TEC gradients (converted to units of range error) are

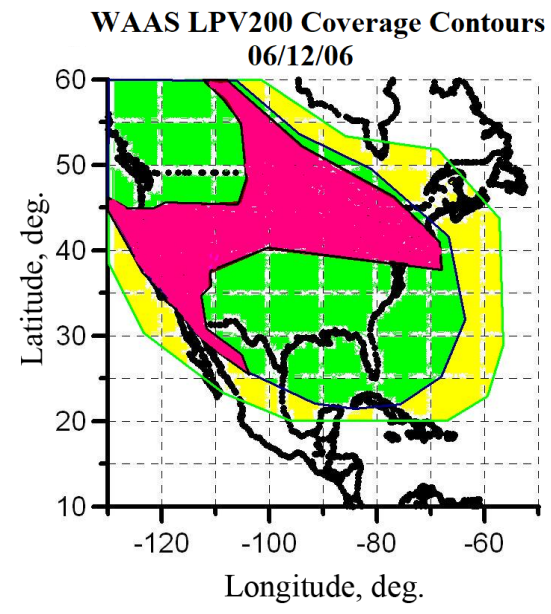

Figure 11. Map of distribution of RNP boundary violation alerts for WAAS users according to LPV200 requirements during the December 6, 2006 extreme solar radio burst. The red color marks the region within which RNP were unavailable; the green color, RNP were available for $>95 \%$ of the observation time; yellow, RNP were available for $<95 \%$ of the observation time (as derived from the results obtained by Carrano et al. [2007])

$\sim 1-3 \mathrm{~mm} / \mathrm{km}$. Under disturbed conditions, this value may increase by two orders of magnitude and amount up to $350 \mathrm{~mm} / \mathrm{km}$ at midlatitudes [Luo et al., 2004] and more than $500 \mathrm{~mm} / \mathrm{km}$ [Saito, Yoshihara, 2017] at equatorial latitudes. Due to the high spatial and temporal variability of ionospheric range errors, currently an attempt is made to limit the size of the LBAS coverage area to $100 \mathrm{~km}$ [Skone, Shrestha, 2002].

There is evidence for precise positioning deterioration when using the RTK and PPP modes in auroral zones. Small-scale ionospheric disturbances, common for this region, cause intense ionospheric scintillations and, as a consequence, positioning deterioration. The data presented in Figure 12 allows us to compare the positioning accuracy deterioration in the RTK and PPP modes, caused by strong variations in TEC and phase scintillations of navigation satellites. The observations were made in the polar ionosphere at the monitoring station Tromsø on March 17 and 18, 2017 [Jacobsen, Schäfer, 2012; Jacobsen, Andalsvik, 2016]. The positioning error increase (Figure 12,c) correlates with the ED irregularity intensity increase (Figure $12, b$ ) and with the occurrence of phase scintillations (Figure 12, a). The positioning error is seen to be able to increase by several orders of magnitude relative to the background level due to scintillations.

Note that if a disturbance region is localized and scintillations occur in a small number of satellitereceiver lines of sight, even without rejection of these measurements the positioning accuracy may remain at the level of undisturbed conditions. In particular, active experiments on heating the ionosphere by powerful short-wave radiation have shown that even when observing intense irregularities in individual satellite- receiver lines of sight the positioning accuracy both in the standard dual-frequency mode and in the PPP mode does not significantly decrease and remains at the background level [Yasyukevich et al., 2020c]. 

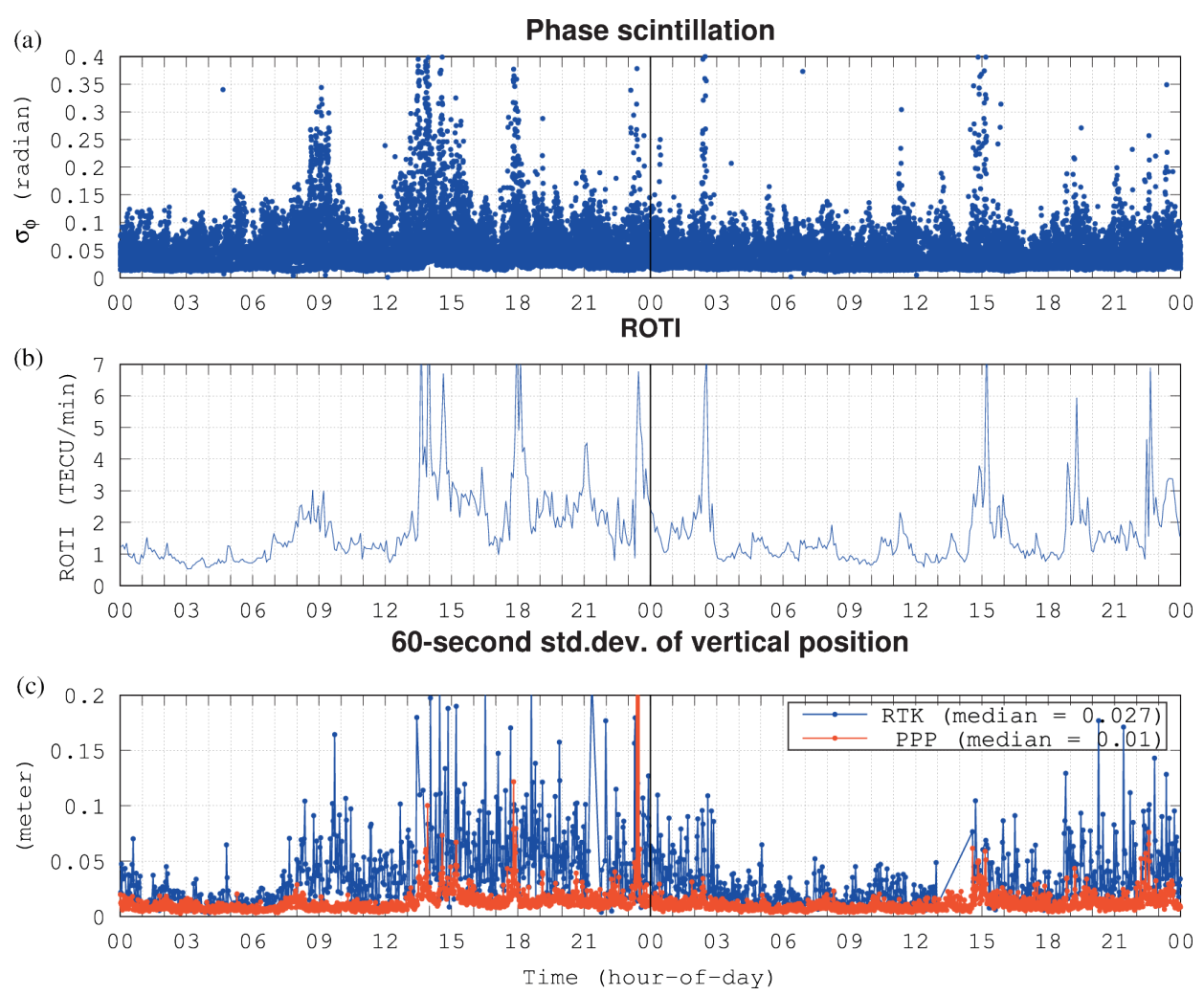

Figure 12. Dynamics of GPS/GLONASS signal phase scintillations $(a)$, ROTI index $(b)$, and a positioning error in a vertical plane $(c)$ in the RTK (blue curve) and PPP (red curve) modes at the station Tromsø on March 17 and 18, 2017. The figure is adapted from [Jacobsen, Andalsvik, 2016]

\section{INTENSITY AND RATE OF OCCURRENCE OF EXTREME SPACE WEATHER EVENTS CRITICAL FOR GNSS PERFORMANCE}

\subsection{Solar radio bursts}

The classification presented in [Huang et al., 2018] divides solar radio bursts with a basic frequency of 1415 $\mathrm{MHz}$ into five classes: minor (G1 class radio flux power $S<100$ s.f.u.), moderate (G2, $100<S<1000$ s.f.u.), strong (G3, $1000<S \leq 10000 \quad$ s.f.u.), severe (G4, $10000<S \leq 100000$ s.f.u.), extreme (extreme, G5, $S>$ 100000 s.f.u.).

In the epoch of experimental observations, the most powerful radio burst was observed on December 6, 2006: according to Owens Valley Solar Array data, the solar radio flux exceeded $10^{6}$ s.f.u. at a frequency of 1.4 $\mathrm{GHz}$ and ranged up to $6.5 \cdot 10^{5}$ and $5 \cdot 10^{5}$ s.f.u. at frequencies of 1.2 and $1.6 \mathrm{GHz}$ respectively [Cerruti et al., 2008]. In this case there is a discrepancy in data from different radio telescopes, which indicates a difficulty in the interpretation of observations of solar radio burst effects [Cerruti et al., 2008]. It is important to note that the most powerful radio burst occurred during solar minimum $23 / 24$, i.e. the power of each individual radio burst is not directly related to the solar activity level, which makes them difficult to predict.

Huang et al. [2018] when analyzing the data for 1997-2016 have found 2384 bursts with $>100$ s.f.u. in the L-band, of which only 17 can be classified as severe and 4 as extreme. Of the remaining events, 1384 were classified as minor and 859 as moderate. In solar cycle 24 due to the lower level of solar activity than in solar cycle 23 , the probability of extreme and severe events decreased significantly. Of particular note among the events occurring during solar cycle 24 are the radio bursts on September 24, 2011 [Sreeja et al., 2013] and September 6, 2017 [Berdermann et al., 2018; Yasyukevich et al., 2018], classified according to [Huang et al., 2018] as extreme and severe respectively.

By processing NOAA annual reports for 1960-2000 [ftp://ftp.ngdc.noaa. gov/STP/swpc_ products/ daily_reports/solar_event_reports] and daily reports on the state of solar activity during the period 2000-2020 [https://www.ngdc.noaa.gov/stp/space-weather/solardata/solar-features/solar-radio/radio-bursts/reports/fixedfrequency-listings], we have collected statistics on G2G5 solar radio bursts. Figure 13 presents the statistics on solar radio bursts at the frequency of $1415 \mathrm{MHz}$ from 1960: the number of days in the year when the maximum detected power of hazardous solar radio emission corresponds to a particular burst class. Data is given on the number of days when the maximum emission corresponds to G3 (orange curve, top panel), G4 (red curve, top panel), G2 (yellow curve, bottom panel), and G2G5 (blue curve, bottom panel) bursts; vertical dark red stripes indicate the years during which extreme G5 bursts occurred.

In general, the statistics on solar radio bursts, including that discussed above and by Giersch et al. [2017], 

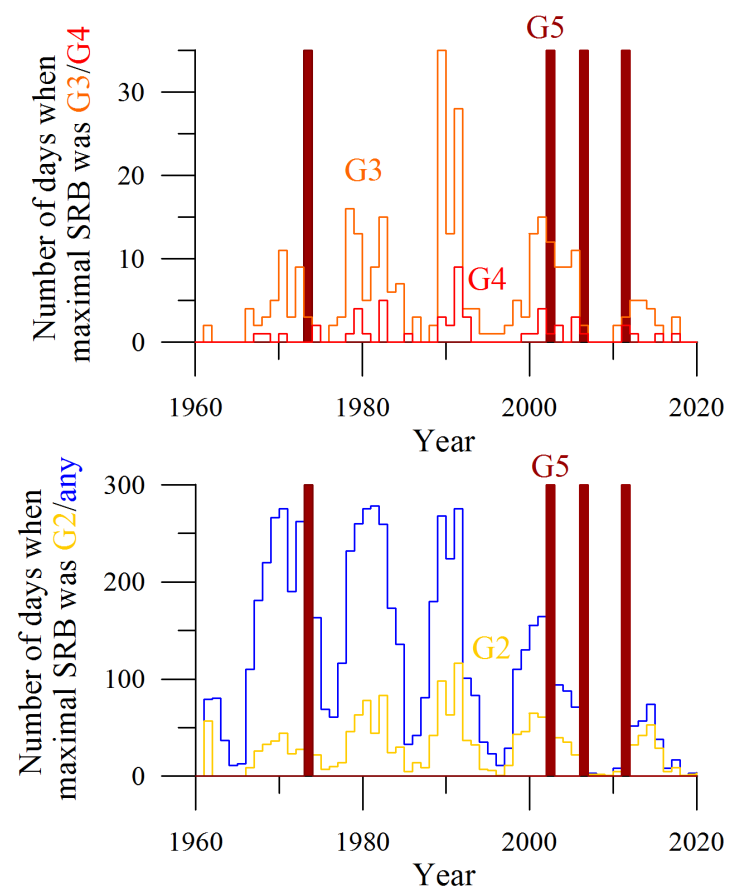

Figure 13. Statistics on G2-G5 solar radio bursts for the period 1960-2020

shows the following: 1) the rate of occurrence of radio bursts varies significantly in different frequency bands; 2) solar cycle is unrelated to the rate of occurrence of powerful radio bursts, and their occurrence does not coincide with solar maxima; 3) the rate of occurrence of solar radio bursts decreases with increasing burst strength, and extreme radio bursts are rare, nonperiodic, and difficult to predict.

All this complicates the forecasting of severe and, moreover, extreme radio bursts on the basis of historical data. Huang et al. [2018] have nonetheless proposed a
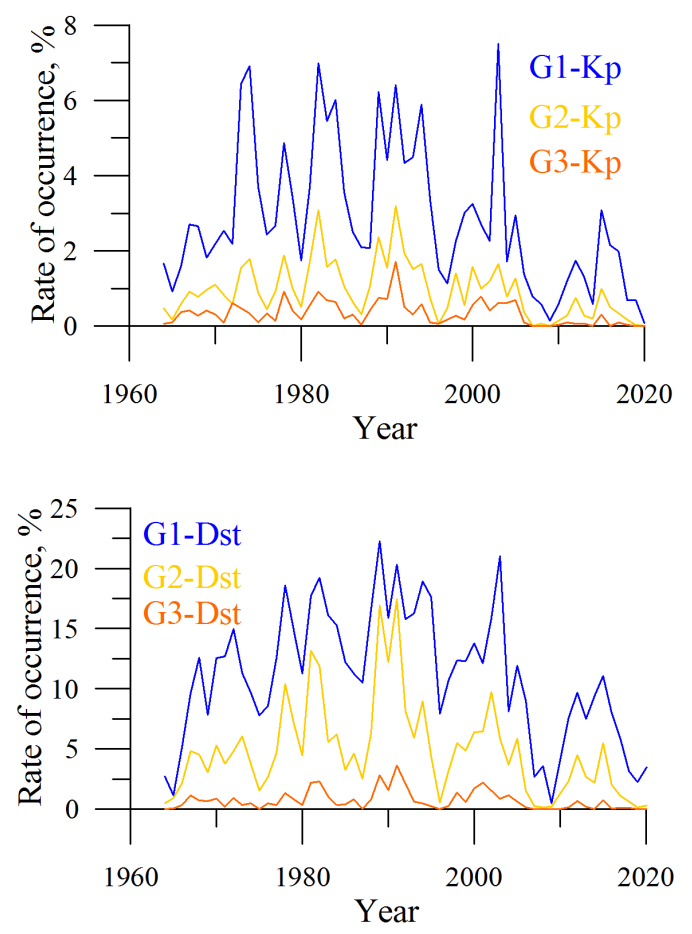

statistical empirical power-law dependence of the frequency of an event (radio bursts in the frequency band $\sim 1-2 \mathrm{GHz}$ ) on its strength:

$$
F(S)=37102 \cdot S^{-1.791} \text {, }
$$

where $S$ is the strength of radio emission flux from the expected burst. For example, at the expected strength $S \geq 4000$ s.f.u. the event rate is $\sim 2.65$ bursts per year.

\subsection{Magnetic storms}

There are two generally accepted independent classifications of magnetic storms — by the planetary geomagnetic activity index $K_{\mathrm{p}}$ [Bartels et al., 1939] and by the Dst index reflecting horizontal geomagnetic field component variations [Loewe, Prölss, 1997]: minor (weak) storm - class G1 $\left(K_{\mathrm{p}}=5, D s t<-30 \mathrm{nT}\right)$, moderate storm - G2 $\left(K_{\mathrm{p}}=6\right.$, Dst $\left.<-50 \mathrm{nT}\right)$, strong storm G3 $\left(K_{\mathrm{p}}=7, D s t<-100 \mathrm{nT}\right)$, severe storm - G4 $\left(K_{\mathrm{p}}=8\right.$, $D s t<-200 \mathrm{nT})$, and extreme storm - G5 $\left(K_{\mathrm{p}}=9\right.$, Dst $<-350$ nT). We should note that the Dst-based classification underestimates storm intensity against the $K_{\mathrm{p}}$-based classification. Averaged $K_{\mathrm{p}}$ values are $4_{0}$ for $\mathrm{G} 1_{\text {Dst }}, 5_{0}$ for $\mathrm{G} 2_{\mathrm{Dst}}, 7$. for $\mathrm{G} 3_{\mathrm{Dst}}, 8_{+}$for $\mathrm{G} 4_{\mathrm{Dst}}$, 9. for G5 $5_{\text {Dst }}$ [Loewe, Prölss, 1997].

On the basis of the OMNIweb database [https://omniweb.sci.gsfc.nasa.gov; King, Papita-shvili, 2005] for 1964-2020, we have prepared statistics on the occurrence of G1-G5 storms.

Figure 14 plots the rate of occurrence of magnetic storms of each class per year during the period considered. The statistics on magnetic storms, classified by the $K_{\mathrm{p}}$ index, is shown in two top panels; and by the $D s t$ index, in two bottom panels. Magnetic storm classes are color-coded: G1 (blue curve); G2 (yellow curve); G3 (orange curve); G4 (red stripes), and G5 (dark-red stripes).
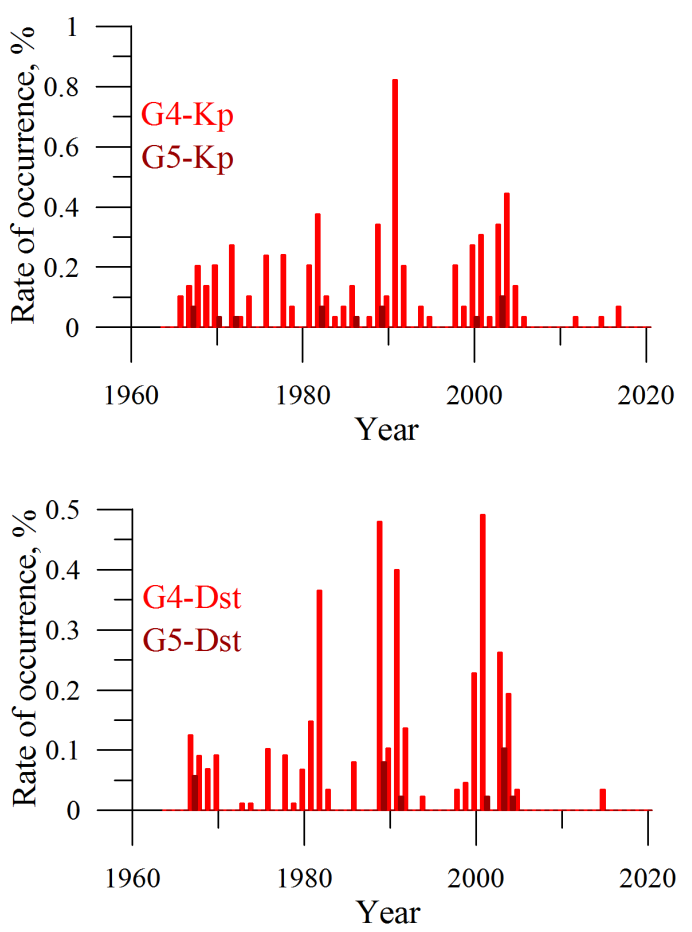

Figure 14. Rate of occurrence of G1-G3 (left) and G4, G5 (right) magnetic storms by years, according to the classification by $K_{\mathrm{p}}$ (top) and $D s t$ (bottom) 
This statistics demonstrates the following: 1) the rate of occurrence of magnetic storms decreases with increasing storm class (i.e. power); 2) all magnetic storm classes exhibit a clear periodicity in increasing and decreasing rate of storm occurrence, which is statistically dependent on solar cycles. The latter circumstance facilitates the prediction of severe and extreme magnetic storms through the analysis of long-period solar observations. Over the period of experimental observations, the most powerful event in near-Earth space is considered to be the Carrington storm (September, 1-2, 1859), during which the Dst index was as great as $-850 \mathrm{nT}$ [Siscoe et al., 2006].

Love et al. [2019] have assumed that the May 15, 1921 storm might have been even more powerful, with Dst $=(-900 \pm 130)$ nT. During the Space Age, the most intense storm occurred on March 13, 1989 (Dst=-640 nT) [Lakhina et al., 2004]. In general, as can be seen from the above observation statistics, severe magnetic storms are fairly rare phenomena. The nature of the distribution of the occurrence rate of intense storms has been discussed extensively. In particular, Riley [2012] has established the power-law character (with a slope of -3.2) of the cumulative distribution function of the rate of occurrence of a magnetic storm with $D s t<-100 \mathrm{nT}$ (Figure 15).

New studies open up further possibilities for improving the accuracy of predicting magnetic storms. For example, Lekshmi et al. [2011] by analyzing data for the last two solar cycles have shown the presence of "UT-effect" for severe magnetic storms: a magnetic storm most often breaks at 00:00 UT, although there is no comprehensive explanation for this effect yet.

As stated above, the main (most probable) drivers of storms are magnetic clouds associated with coronal mass ejections. A magnetic storm is much less often driven by corotating interaction regions (CIR), ejecta, and sheath. For example, the rate of occurrence of a magnetic storm with Dst -50 nT due to CIR, ejecta, or sheath, is 3-4 times lower than that of a CME associated magnetic storm with the same intensity. For more powerful magnetic storms with Dst $-200 \mathrm{nT}$, the respective rate is already lower 5-15 times [Yermolaev et al., 2013]. In general, we may state that the technique for predicting magnetic storms of a given intensity does not satisfy practical requirements yet and needs further improvement.
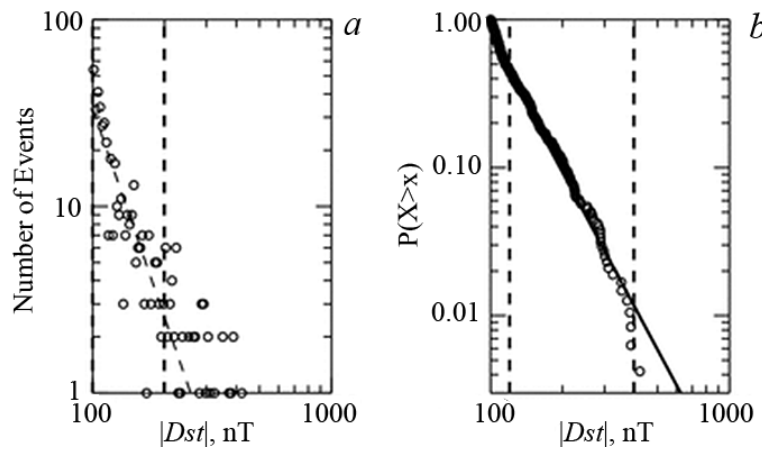

Figure 15. Observed number of magnetic storms of various intensities $(a)$ and the cumulative distribution function of the rate of occurrence of magnetic storm with an intensity of $\mathrm{X}>\mathrm{X}(b)$. Figure 8 is adopted from [Riley, 2012]

\section{CONCLUSIONS}

The data given above shows extreme space weather events can cause significant deterioration in GNSS performance and their augmentations. Analysis of the problem allows us to identify the following avenues for the improvement of GNSS:

a) to improve the accuracy in measuring ranging parameters during extreme space weather events;

b) to improve the control of system integrity and availability of required navigation parameters for GNSS users.

Improving the accuracy in ranging parameters suggests a maximum decrease in systematic and random phase or pseudodelay errors under conditions of geomagnetic disturbances, ionospheric irregularities, and powerful solar radio bursts. In the standalone navigation mode, this can be achieved in the following ways:

1) using models or near-real-time updated maps for correcting ionospheric range errors;

2) tuning adaptive lock loop;

3) decreasing thermal noise of RF chain of a receiver and hence decreasing the threshold signal-to-noise ratio, which determines the stability of lock loop and accuracy in ranging parameters;

4) using PRN codes having the best cross-correlation features and potential measurement accuracy.

Ways 1 and 4 reduce the systematic range error and increase the potential precision of ranging measurements. The use of models of ionospheric range error is not always sufficiently effective even under quiet conditions, not to mention geomagnetic storms. An alternative may be to use global or local/regional TEC maps in near-real time [Li et al., 2020].

New-generation GNSS satellites employ range code signals with improved structure. Specifically, two new civilian signals at frequencies L2 (L2C), and L5 have been added to GPS. Thus, the new-generation GPS satellites emit civilian signals at three frequencies: L1 (1575.42 MHz), L2 (1227.6 MHz), and L5 (1176.45 $\mathrm{MHz}$ ). Extension of the signal set opens up great opportunities for reducing errors in range measurements during extreme heliogeophysical events: the L1 signal has the smallest refractive error, the L5 signal features higher strength, the L2C and L5 signals contain long range codes (10 times longer than the C/A code), which facilitates the improvement of signal cross-correlation features, in particular under multipath and low signal-tonoise ratio conditions.

Ways 2 and 3 may effectively reduce random ranging errors. These ways would be effective in a posteriori monitoring of accuracy and continuity in measuring signal parameters under given heliogeophysical conditions. Optimum lock loop tuning requires prior statistically significant observations of the time stationarity of measured parameters under intense ionospheric scintillations. In this case, it should be borne in mind that the installation of a navigation receiver at highly dynamic objects (aircraft, high-speed ground transport) limits adaptive lock loop tuning. 
Space weather events are the main cause of the differential mode deterioration - their effect is significant for both wide-area and local augmentation systems. It is however recommended to give priority to LBAS for precise positioning during extreme space weather events. The stability of wide area augmentation systems can be increased through measurements from available local reference stations of augmentations, as well as from geophysical and geodetic monitoring networks (IGS, CORS, etc.).

A quite important direction of GNSS modernization involves improving the system integrity control and the control of availability of required navigation parameters with respect to space weather effects. We can recommend the following technical procedures:

1) to modernize the receiver autonomous integrity monitoring (RAIM) by introducing solutions taking into account current geophysical conditions;

2) to modernize the control of availability of required navigation parameters of GNSS users in the differential navigation mode by introducing solutions taking into account current geophysical conditions;

3) to improve techniques for long-term forecasting and nowcasting of availability of GNSS users' required navigation parameters during heliogeomagnetic disturbances.

To complement RAIM, we can recommend to perform continuous monitoring of the scintillation index $S_{4}$ in the channel for tracking signals from each GNSS satellite. The scintillation index value in the channel for tracking a particular satellite can serve as an effective near-real-time indicator of environment during integrity control under geomagnetic disturbances: a positioning procedure can eliminate range measurements from the satellites recording intense scintillations $\left(S_{4}>0.6\right)$. This leaves open the question about the optimal data set to estimate $S_{4}$ depending on intensity and type of heliogeophysical event, mean signal power at the reception point, and parameters of PRN code sequence.

Modernization of the control of RNP availability for WAAS users must be focused on improving the process for forming the ionospheric component of differential correction. We may recommend to separate the formation of globally- and locally-dependent differential corrections to range errors by engaging the available means of LBAS and geophysical/geodetic measurement data for estimating the latter. In particular, the use of sample estimates of ionospheric range errors obtained by the aforementioned means will lead to a significant reduction in the probability of false alert and dangerous mismatch in the control of RNP availability of WAAS users.

Long-term forecasting and nowcasting of RNP availability during a heliogeomagnetic disturbance are the most controversial and difficult directions of GNSS modernization. We have demonstrated above that extreme heliogeomagnetic events can cause serious GNSS performance deterioration, but there is no direct functional relationship here. First of all, we should separate the problems of forecasting effects of solar radio bursts and powerful geomagnetic disturbances on GNSS performance. One of the ways to increase the reliability of the forecasts may be the development of a system of geomagnetic activity indices having the best correlation with GNSS performance characteristics.

The current state of research into the mechanisms of formation of solar radio bursts does not allow sufficiently accurate long-term forecasting of severe solar radio bursts in the interests of GNSS users. The only way recommended so far may be continuous radio monitoring of the Sun with rapid alert issued to users when radio bursts of $>10^{3}$ s.f.u. occur.

The long-term forecasting of the geomagnetic phenomena dangerous for GNSS performance should build on reliable prediction of geomagnetic disturbances as such. This is a difficult scientific problem that is still far from being solved at a level sufficient to reliably predict GNSS performance during magnetic storms. Solving it successfully requires the deployment of a global service for monitoring of the Sun and a global space weather forecast system (similar to the integration of groundbased and space-born navigation means as part of the worldwide GNSS system). This service must be supported by scientific infrastructure including newgeneration monitoring instruments [Zherebtsov, 2020].

In conclusion, we note that there are virtually all elements necessary for the deployment of a complex system for monitoring and providing GNSS required navigation parameters (and their augmentations) under conditions of adverse heliogeophysical events. In the future, there is a need to develop a service for global monitoring and prediction of GNSS performance.

The reported study was funded by RFBR, project number 20-15-50079. We are grateful to D.A. Zatolokin and F. Zhou for the software used to calculate coordinates. We acknowledge use of NASA/GSFC's Space Physics Data Facility's OMNIWeb (or CDAWeb or ftp) service, and OMNI data, and the International GNSS Service (IGS).

\section{REFERENCES}

Aa E., Huang W., Liu S., Ridley A., Zou S., Shi L., Chen Y., Shen H., Yuan T., Li J., Wang T. Midlatitude plasma bubbles over China and adjacent areas during a magnetic storm on 8 September 2017. Space Weather. 2018, vol. 16, pp. 321-331. DOI: 10.1002/2017SW001776.

Aarons J. Global morphology of ionospheric scintillations. Proc. of the IEEE. 1982, vol. 70, no. 4, pp. 360-378. DOI: 10.1109/PROC.1982.12314.

Afraimovich E.L., Perevalova N.P. GPS-monitoring verkhnei atmosfery Zemli [GPS monitoring of the Earth's upper atmosphere]. Irkutsk, 2006, 480 p. (In Russian).

Afraimovich E.L., Lesyuta O.S., Ushakov I.I. Voeykov S.V. Geomagnetic storms and the occurrence of phase slips in the reception of GPS signals. Ann. Geophys. 2002, vol. 45, no. 1, pp. 55-71. DOI: 10.4401/ag-3494.

Afraimovich E.L., Demyanov V.V., Ishin A.B. Smolkov G.Ya. Powerful solar radio bursts as a global and free tool for testing satellite broadband radio systems, including GPS-GLONASS-GALILEO. J. Atmos. Solar-Terr. Phys. 2008, vol. 70, no 15, pp. 1985-1994. DOI: 10.1016/j.jastp. 2008.09.008.

Afraimovich E.L., Astafyeva E.I., Demyanov V.V. Gamayunov I.F. Mid-latitude amplitude scintillation of GPS signals and GPS performance slips. Adv. Space Res. 2009a, vol. 43, iss. 6, pp. 964-972. DOI: 10.1016/j.asr.2008.09.015. 
Afraimovich E.L., Demyanov V.V., Gavrilyuk N.S., Ishin A.B., Smolkov G.Ya. Malfunction of satellite navigation systems GPS and GLONASS caused by powerful radio emission of the Sun during solar flares on December 6 and 13, 2006, and October 28, 2003. Cosmic Res. 2009b, vol. 47, pp. 126-137. DOI: 10.1134/S001095250902004X.

Akasofu S.I., Chapman S. Solar-Terrestrial Physics. Chapter 2. Oxford University Press, 1972, 901. p.

Anderson P.C., Straus P.R. Magnetic field orientation control of GPS occultation observations of equatorial scintillation. Geophys. Res. Lett. 2005, vol. 32, L21107. DOI: 10.1029/ 2005 GL023781.

Astafyeva E., Yasyukevich Y., Maksikov A., Zhivetiev I. Geomagnetic storms, super-storms, and their impacts on GPSbased navigation systems. Space Weather. 2014, vol. 12, no. 7, pp. 508-525. DOI: 10.1002/2014SW001072.

Barabanova L.P. Minimization of GNSS geometric factors. J. Comput. Syst. Sci. Int. 2010, vol. 49, pp. 310-317. DOI: $10.1134 /$ S1064230710020164.

Bartels J., Heck N.H., Johnston H.F. The three-hour-range index measuring geomagnetic activity. Terrestrial Magnetism and Atmospheric Electricity. 1939, vol. 44, no. 4, pp. 411454. DOI: 10.1029/ TE044i004p00411.

Bazarzhapov A.D., Matveev M.I., Mishin V.M. Geomagnitnye variacii $i$ buri [Geomagnetic variations and storms] Novosibirsk, Nauka Publ., 1979, 287 p. (In Russian).

BDS-SIS-ICD. BeiDou Navigation Satellite System Signal In Space Interface Control Document: Open Service Signal B1I (Version 3.0). 2019. BDS-SIS-ICD-B1I-3.0. 2019-02.

Berdermann J., Kriegel M., Banyś D., Heymann F., Hoque M.M., Wilken V., Borries C., Heßelbarth A., Jakowski N. Ionospheric response to the X9.3 Flare on 6 September 2017 and its implication for navigation services over Europe. Space Weather. 2018, vol. 16, iss. 10, pp. 1604-1615. DOI: $10.1029 / 2018$ SW001933.

Berghmans D., Van der Linden R.A.M., Vanlommel P., Warnant R., Zhukov A., Robbrecht E., et al. Solar activity: nowcasting and forecasting at the SIDC. Ann. Geophys. 2005 , vol. 23 , no. 6 , pp. 3115-3128. DOI: 10.5194/angeo-23-31152005.

Bhattacharrya A., Yen K.C., Franke S.J. Deducing turbulence parameters from transionospheric scintillation measurements. Space Sci. Rew. 1992, vol. 61, pp. 335-386. DOI: 10.1007/BF00222311.

Bruyninx C., Habrich H., Söhne W., Kenyeres A., Stangl G., Völksen C. Enhancement of the EUREF Permanent Network Services and Products. Geodesy for Planet Earth. IAG Symposia Series. 2012, vol. 136, pp. 27-35. DOI: 10.1007/978-3-642-20338-1 4.

Bruzek A., Durrant C.J. Illustrated Glossary for Solar and Solar-Terrestrial Physics. 1977, 207 p. DOI: 10.1007/978-94010-1245-4.

Carrano C.S., Groves K.M., Bridgwood C.T. Effects of the December 2006 Solar Radio Bursts on the GPS Receivers of the AFRL-SCINDA Network // Proc. of the International Beacon Satellite Symposium, Boston College. June 11-15, 2007.

Carrano C.S., Bridgwood C.T., Groves K.M. Impacts of the December 2006 solar radio bursts on the performance of GPS Radio Sci. 2009, vol. 44, RS0A25. DOI: 10.1029/2008RS004071.

Cerruti A.P., Kintner P.M., Gary D.E., Lanzerotti L.J., de Paula E.R., Vo H.B. Observed Solar Radio Burst Effects on GPS/WAAS Carrier-to-Noise Ratio. Space Weather. 2006, vol. 4, S10006. DOI: 10.1029/2006SW000254.

Cerruti A.P., Kintner P.M., Gary D.E. Effect of intense December 2006 solar radio bursts on GPS receivers. Space Weather. 2008, vol. 6, S10D07. DOI: 10.1029/2007SW000375.

Chen Z., Gao Y., Liu Z. Evaluation of solar radio bursts' effect on GPS receiver signal tracking within International GPS Service network. Radio Sci. 2005, vol. 40, RS3012. DOI: 10.1029/2004RS003066.
Cherniak I., Zakharenkova I. First observations of super plasma bubbles in Europe. Geophys. Res. Lett. 2016, vol. 43, no. 21, pp. 11137-11145. DOI: 10.1002/2016GL071421.

Conker R.S., El-Arini M.B., Hegarty C.J., Hsiao T. Modeling the effects of ionospheric scintillation on GPS/SatelliteBased Augmentation System availability. Radio Sci. vol. 38, no. 1, 1001. DOI: 10.1029/2000RS002604.

Coster A.J., Foster J.C., Erickson P.J., Rich F.J. Regional GPS mapping of storm enhanced density during the July 15 162000 geomagnetic storm. Proceedings of International Beaco Satellite Symposium, June 4-6, 2001. Boston College; Institute for Scientific Research. USA: Chestnut Hill, MA. 2001, pp. 176-180.

Dabove P., Linty N., Dovis F. Analysis of multiconstellation GNSS PPP solutions under phase scintillations at high latitudes. Appl. Geomatics. 2020, vol. 12, pp. 45-52. DOI: $10.1007 / \mathrm{s} 12518-019-00269-4$.

Demyanov V.V., Yasyukevich Yu.V. Mekhanizmy vozdeistviya neregulyarnykh geofizicheskikh faktorov na funktsionirovanie sputnikovykh radionavigatsionnykh system [Mechanisms of impact of irregular geophysical factors on operation of radio positioning satellite systems], Irkutsk, Irkutsk State University Publ., 2014, 349 p. (In Russian).

Demyanov V.V., Afraimovich E.L., Jin S. An evaluation of potential solar radio emission power threat on GPS and GLONASS performance. GPS Solutions. 2012a, vol. 16, pp. 411-424. DOI: 10.1007/s10291-011-0241-9.

Demyanov V.V., Yasyukevich Y.V., Ishin A.B., Astafyeva E.I. Ionospheric super-bubble effects on the GPS positioning relative to the orientation of signal path and geomagnetic field direction. GPS Solutions. 2012b, vol. 16, pp. 181-189. DOI: 10.1007/s10291-011-0217-9.

Demyanov V., Zhang X., Lu X. Moderate geomagnetic storm condition, WAAS Alerts and real GPS positioning quality. J. Atmos. Sci. Res. 2019, vol. 2, no. 1, pp. 10-23. DOI: 10.30564/jasr.v2i1.343.

Dow J.M., Neilan R.E., Rizos C. The International GNSS Service in a changing landscape of Global Navigation Satellite Systems. J. Geodesy. 2009, vol. 83, pp. 191-198. DOI: $10.1007 / \mathrm{s} 0019000803003$.

Dulk A.G. Radio emission from the Sun and stars. Ann. Rev. Astron. Astrophys. 1985. vol. 23, pp. 169-224. DOI: 10.1146/ annurev.aa.23.090185.001125.

Falcone M., Lucas R., Burger T., Hein G.W. The European Galileo programme. The European EGNOS project. ESA Publications Division, Noordwijk, The Netherlands, SP-1303. 2006, pp. 435-455.

Freymueller J.T. AEIC (Kodiak) 2014. GPS/GNSS Observations Dataset. The GAGE Facility operated by UNAVCO, Inc., 2017.

Galileo-SIS-ICD. European GNSS (Galileo) open service. Signal-in-space interface control document. Issue 2.0, January 2021.

Giersch O.D., Kennewell J., Lynch M. Solar radio burst statistics and implications for space weather effects. Space Weather. 2017, vol. 15, pp. 1511-1522. DOI: 10.1002/2017SW001658

GPS-WAAS-PS. Global Positioning System Wide Area Augmentation System (WAAS) Performance Standard. 2008-10.

Gulyaeva T.L., Gulyaev R.A. Chain of responses of geomagnetic and ionospheric storms to a bunch of central coronal hole and high speed stream of solar wind. J. Atmos. Solar-Terr. Phys. 2020, vol. 208, 105380. DOI: 10.1016/j.jastp.2020.105380.

Hargreaves J.K. The Upper Atmosphere and SolarTerrestrial Relations. New York, Van Nostrand Reinhold Co. 1979, $312 \mathrm{p}$

Hernandez-Pajares M., Juan J.M., Sanz J., Orus R., Garcia-Rigo A., Feltens J., Komjathy A., Schaer S.C., Krankowski A. The IGS VTEC maps: a reliable source of ionospheric 
information since 1998. J. Geodesy. 2009, vol. 83, no 3, pp 263-275. DOI: 10.1007/s00190-008-0266-1.

Hofmann-Wellenhof B., Lichtenegger H., Collins J. Global Positioning System: Theory and Practice. 5th edition. New York, Springer-Verlag, 2001. 406 p. DOI: 10.1007/987-37091-6199-9.

Huang C.-S., de La Beaujardiere O., Roddy P.A., Hunton D.E., Pfaff R.F., Valladares C.E., Ballenthin J.O. Evolution of equatorial ionospheric plasma bubbles and formation of broad plasma depletions measured by the C/NOFS satellite during deep solar minimum. J. Geophys. Res.: Space Phys. 2011, vol. 116, no. A3, A03309. DOI: 10.1029/2010JA015982.

Huang W., Aa E., Shen H., Liu S. Statistical study of GNSS L-band solar radio bursts. GPS Solutions. 2018, vol. 22, 114. DOI: 10.1007/s10291-018-0780-4.

IKD SDKM. Sistema differencial'noj korrekcii $i$ monitoring $a$ [System for differential correction and monitoring]: $1^{\text {st }}$ edition. 2011. (In Russian). 133 p.

Jacobsen K.S., Schäfer S. Observed effects of a geomagnetic storm on an RTK positioning network at high latitudes. J. Space Weather Space Clim. 2012, vol. 2, A13. DOI: $10.1051 / \mathrm{swsc} / 2012013$.

Jacobsen K.S., Andalsvik Y.L. Overview of the 2015 St. Patrick's day storm and its consequences for RTK and PPP positioning in Norway. J. Space Weather Space Clim. 2016, vol. 6, A9. DOI: $10.1051 / \mathrm{swsc} / 2016004$.

Jayachandran P.T., Langley R.B., MacDougall J.W., Mushini S.C., Pokhotelov D., Hamza A.M., Mann I.R., Milling D.K., Kale Z.C., Chadwick R., Kelly T., Danskin D.W., Carrano C.S. Canadian High Arctic Ionospheric Network (CHAIN). Radio Sci. 2009, vol. 44, no. 1, RS0A03. DOI: 10.1029/2008RS004046.

Jin S., Cardellach E., Xie F. GNSS Remote Sensing: Theory, Methods and Applications, Remote Sensing and Digital Image Processing. 2014, vol. 19, 276 p. DOI: 10.1007/978-94007-7482-7.

Kaplan E.D. Understanding GPS: principles and applications. 1996, $556 \mathrm{p}$.

King J.H., Papitashvili N.E. Solar wind spatial scales in and comparisons of hourly Wind and ACE plasma and magnetic field data. J. Geophys. Res.: Space Phys. 2005, vol. 110, no. A2, A02104. DOI: 10.1029/2004JA010649.

Klobuchar J.A., Kunches J.M., Van Dierendonck A.J. Eye on the ionosphere: Potential solar radio burst effects on GPS signal to noise. GPS Solutions. 1999, vol. 3, no. 2, pp. 69-71. DOI: 10.1007/PL00012794.

Kolesnik S.N., Tinin M.V., Afanasiev N.T. Statistical characteristics of a wave propagating through a layer with random irregularities. Waves in Random Media. 2002, vol. 12, pp. 417-431. DOI: 10.1088/0959-7174/12/4/302.

Kozyreva O.V., Pilipenko V.A., Zakharov V.I., Engebretson M.J. GPS-TEC response to the substorm onset during April 5, 2010, magnetic storm. GPS Solutions. 2017, vol. 21, no. 3, pp. 927-936. DOI: 10.1007/s10291-016-0581-6.

Kravtsov A.Y. Prohozhdenie radiovoln cherez ionosferu Zemli [Propagation of radio waves in the Earth ionosphere]. Moscow, Radio i svyaz' Publ., 1983, 224 p. (In Russian).

Lakhina G., Alex S., Tsurutani B., Gonzalez W. Research on Historical Records of Geomagnetic Storms. Proceedings of the International Astronomical Union, 2004(IAUS226). 2004, pp. 3-15. DOI: 10.1017/S1743921305000074.

Lekshmi V.D., Balan N., Tulasi S.R., Liu J.-Y. Statistics of geomagnetic storms and ionospheric storms at low and mid latitudes in two solar cycles. J. Geophys. Res.: Space Phys. 2011, vol. 116, A11328. DOI: 10.1029/2011JA017042.

Li Z., Wang N., Hernández-Pajares M., Yuan Y., Krankowski A., Liu A., Zha J., et al. IGS real-time service for global ionospheric total electron content modeling. J. Geodesy.
2020, vol. 94, 32. DOI: 10.1007/s00190-020-01360-0.

Linty N. Codeless tracking algorithms for GNSS software receivers: Tesi di Laurea Magistrale. Torino. 2010, 126 p.

Linty N., Minetto A., Dovis F., Spogli L. Effects of phase scintillation on the GNSS positioning error during the September 2017 storm at Svalbard. Space Weather. 2018, vol. 16, pp. 1317-1329. DOI: 10.1029/2018SW001940.

Loewe C.A., Prölss G.W. Classification and mean behavior of magnetic storms. J. Geophys. Res. 1997, vol. 102, no. A7, pp. 14209-14213. DOI: 10.1029/96JA04020.

Love J.J., Hayakawa H., Cliver E.W. Intensity and impact of the New York Railroad superstorm of May 1921. Space Weather. 2019, vol. 17, pp. 1281-1292. DOI: 10.1029/2019SW002250.

Luo M., Pullen S., Ene A., Qiu D., Walter T., Enge P. Ionosphere threat to LAAS: updated model, user impact, and mitigations. $17^{\text {th }}$ International Technical Meeting of the Satellite Division (ION GNSS 2004). Long Beach, 2004, pp. 27712785.

Luo X., Gu S., Lou Y., Xiong C., Chen B., Jin X. Assessing the performance of GPS precise point positioning under different geomagnetic storm conditions during solar cycle 24. Sensors. 2018, vol. 18, no. 6, 1784. DOI: 10.3390/s18061784.

Luo X., Gu S., Lou Y., Song W. Better thresholds and weights to improve GNSS PPP under ionospheric scintillation activity at low latitudes. GPS Solutions. 2020, vol. 24, 17. DOI: 10.1007/s10291-019-0924-1.

Ma G., Maruyama T. A super bubble detected by dense GPS network at East Asian longitudes. Geophys. Res. Lett. 2006, vol. 33, no. 21, L21103. DOI: 10.1029/2006GL027512.

McCaffrey A.M., Jayachandran P.T. Spectral characteristics of auroral region scintillation using $100 \mathrm{~Hz}$ sampling. GPS Solutions. 2017, vol. 21, pp. 1883-1894. DOI: 10.1007/s10291017-0664-z.

Michalek G., Puchowska K., Rams A. Statistical analysis of decimetric radio bursts, flares and coronal mass ejections. Solar Phys. 2009, vol. 257, pp. 113-124. DOI: 10.1007/s11207-0099343-8.

Moreno B., Radicella S., de Lacy M.C., Herraiz M., Rodriguez-Caderot G. On the effects of the ionospheric disturbances on precise point positioning at equatorial latitudes. GPS Solutions. 2011, vol. 15, N 4, pp. 381-390. DOI: 10.1007/s10291-010-0197-1.

Pashintsev V.P., Akhmadeev R.R., Prediction noise immunity of satellite communications system and navigation according to GPS-monitoring ionosphere. Elektrosvyaz, 2015, no. 11 , pp. 32-38. (In Russian).

Pashintsev V.P., Gamov M.V. Influence of dispersion ionosphere on pseudo range measurements in satellite radio navigation systems. Radioelectron. Commun. Syst. 2002, vol. 45, no. 12 , pp. $3-13$.

Psiaki M.L. Block acquisition of weak GPS signals in a software receiver. Proc. ION GPS 2001, Salt Lake City, UT, September 11-14, 2001, pp. 2838-2850.

Riley P. On the probability of occurrence of extreme space weather events. Space Weather. 2012, vol. 10, S02012. DOI: 10.1029/2011SW000734.

Rino C.L. The Theory of Scintillation with Applications in Remote Sensing. Hoboken, NJ, John Wiley \& Sons, Inc., 2011, 230 p. DOI: 10.1002/9781118010211.

Rodríguez-Bilbao I., Radicella S.M., Rodríguez-Caderot G., Herraiz M. Precise point positioning performance in the presence of the 28 October 2003 sudden increase in total electron content. Space Weather. 2015, vol. 13, pp. 698-708. DOI: 10.1002/2015SW001201.

Saito S., Yoshihara T. Evaluation of extreme ionospheric total electron content gradient associated with plasma bubbles for GNSS Ground-Based Augmentation System. Radio Sci. 
2017, vol. 52, pp. 951-962. DOI: 10.1002/2017RS006291.

Shi C., Liu J. GNSS status and developments in China. Presentation at the Civil Global Positioning System Service Interface Committee, $46^{\text {th }}$ meeting, Fort Worth, Texas, September 26. 2006.

Siscoe G., Crooker N.U., Clauer C. Dst of the Carrington storm of 1859. Adv. Space Res. 2006, vol. 38, iss. 2, pp. 173 179. DOI: $10.1016 /$ j.asr.2005.02.102.

Skone S., Shrestha S.M. Limitations in DGPS positioning accuracies at low latitudes during solar maximum. Geophys. Res. Lett. 2002, vol. 29, no. 10, p. 81-1-81-4. DOI: 10.1029/ 2001GL013854.

Smith J., Heelis R.A. Equatorial plasma bubbles: Variations of occurrence and spatial scale in local time, longitude, season, and solar activity. J. Geophys. Res.: Space Phys. 2017, vol. 122, pp. 5743-5755. DOI: 10.1002/2017JA024128.

Sreeja V., Aquino M., Jong K. Impact of the 24 September 2011 solar radio burst on the performance of GNSS receivers. Space Weather. 2013, vol. 11, pp. 306-312. DOI: 10.1002/ swe.20057.

Vadakke S.V., Aquino M., Marques H.A., Moraes A. Mitigation of ionospheric scintillation effects on GNSS precise point positioning (PPP) at low latitudes. J. Geodesy. 2020, vol 94, 15. DOI: 10.1007/s00190-020-01345-z.

Vani B.C., Forte B., Monico J.F.G., Skone S., Shimabukuro M.H., Moraes A., Portellla I.P., Marques H.A. A Novel Approach to Improve GNSS Precise Point Positioning During Strong Ionospheric Scintillation: Theory and Demonstration. IEEE Transactions on Vehicular Technology. 2019, vol. 68, no 5, pp. 4391-4403. DOI: 10.1109/TVT.2019.2903988.

Vdovin V.S., Dvorkin V.V., Karpik A.P., Lipatnikov L.A., Sorokin S.D., Steblov G.M. Current state and future development of active satellite geodetic networks in Russia and their integration into ITRF. Vestnik SGUGiT [Vestnik (Bulletin) of the Siberian State University of Geosystems and Technologies (SSUGT)]. 2018, vol. 23, no. 1, pp. 6-27. (In Russian).

Warnant R., Lejeune S., Bavier M. Space weather influence on satellite-based navigation and precise positioning. Space Weather. 2007, vol. 344, pp. 129-146. DOI: 10.1007/14020-5446-7 14.

Yakovlev O.I. Kosmicheskaya radiofizika [Space radio physics]. Voronezh, Nauchnaya kniga Publ., 1998, 432 p. (In Russian).

Yasyukevich Y., Astafyeva E., Padokhin A., Ivanova V., Syrovatskii S., Podlesnyi A. The 6 September 2017 X-class solar flares and their impacts on the ionosphere, GNSS, and HF radio wave propagation. Space Weather. 2018, vol. 16, pp. 1013-1027. DOI: 10.1029/2018SW001932.

Yasyukevich Yu.V., Kiselev A.V., Zhivetiev I.V., Edemskiy I.K., Syrovatskii S.V., Maletckii B.M., Vesnin A.M. SIMuRG: System for Ionosphere Monitoring and Research from GNSS. GPS Solutions. 2020a, vol. 24, 69. DOI: 10.1007/s10291-020-00983-2.

Yasyukevich Y., Vasilyev R., Ratovsky K. Small-scale ionospheric irregularities of auroral origin at mid-latitudes during the 22 June 2015 magnetic storm and their effect on GPS positioning. Remote Sensing. 2020b, vol. 12, no 10 , 1579. DOI: $10.3390 / \mathrm{rs} 12101579$.

Yasyukevich Yu.V., Syrovatskiy S.V., Padokhin A.M., Frolov V.L., Vesnin A.M., Zatolokin D.A., Kurbatov G.A., Zagretdinov R.V., Pershin A.V., Yasyukevich A.S. GPS positioning accuracy in different modes with active forcing on the ionosphere from the SURA high-power HF radiation. Radiophysics and Quantum Electronics. 2020c, vol. 62, pp. 807-819. DOI: 10.1007/s11141-020-10026-y.

Yasyukevich Yu.V., Yasyukevich A.S., Astafyeva E.I. How modernized and strengthened GPS signals enhance the system performance during solar radio bursts. GPS Solutions. 2021, vol. 25, 46. DOI: 10.1007/s10291-021-01091-5.
Yermolaev Y.I., Lodkina I.G., Nikolaeva N.S., Yermolaev M.Y. Occurrence rate of extreme magnetic storms. $J$. Geophys. Res.: Space Phys. 2013, vol. 118, pp. 4760-4765. DOI: 10.1002/jgra.50467.

Zakharov V.I., Chernyshov A.A., Miloch W., Jin Y. Influence of the ionosphere on the parameters of the GPS navigation signals during a geomagnetic substorm. Geomagnetism and Aeronomy. 2020, vol. 60, pp. 754-767. DOI: 10.1134/S00 16793220060158.

Zatolokin D.A. Programma resheniya navigatsionnoi zadachi GNSS «Navi»: Svidetel'stvo o gosudarstvennoi registratsii programmy EVM № 2020612010 [Program Navi for GNSS positioning. Certificate of State Registration No. 2020612010]. 2020. (In Russian).

Zherebtsov G.A. Complex of heliogeophysical instruments of new generation. Solar-Terr. Phys. 2020, vol. 6, no. 2, pp. 3-13. DOI: 10.12737/stp-62202001.

Zhang X., Guo F., Zhou P. Improved precise point positioning in the presence of ionospheric scintillation. GPS Solutions. 2014, vol. 18, pp. 51-60. DOI: 10.1007/s10291-012-0309-1.

Zhou F., Dong D., Li W., Jiang X., Wickert J., Schuh H. GAMP: An open-source software of multi-GNSS precise point positioning using undifferenced and uncombined observations. GPS Solutions. 2018, vol. 22, 33. DOI: 10.1007/s10291-0180699-9.

Zumberge J.F., Heflin M.B., Jefferson D.C. Precise point positioning for the efficient and robust analysis of GPS data from large networks. J. Geophys. Res.: Solid Earth. 1997, vol. 102, no. B3. pp. 5005-5017. DOI: 10.1029/96JB03860.

URL: $\quad$ https://qzss.go.jp/en/technical/download/pdf/ps-isqzss/is-qzss-16-001.pdf (accessed February 1, 2021).

URL: https://www.isro.gov.in/sites/default/files/irnss_sps_ icd version1.1-2017.pdf (accessed February 1, 2021).

URL: https://www.sonel.org (accessed February 1, 2021).

URL: https://hive.geosystems.aero (accessed February 1, 2021).

URL: https://eft-cors.ru (accessed February 1, 2021).

URL: https://kb.igs.org/hc/en-us/articles/201096516-IGSFormats (accessed February 1, 2021).

URL: http:/gps.ece.cornell.edu/briefs.php (accessed March 25, 2021)

URL: https://www.ngdc.noaa.gov/stp/space-weather/solardata/solar-features/solar-radio/rstn-1-second http://radiosun.ts.astro.it(accessed March 25, 2021).

URL: https://gps.gov/technical/icwg/IS-GPS-200J.pdf (accessed March 25, 2021).

URL: https://www.nstb.tc.faa.gov/DisplayArchive.htm (accessed February 1, 2021).

URL: ftp://ftp.ngdc.noaa.gov/STP/swpc products/daily reports /solar_event_reports (accessed February 1, 2021).

URL: https://omniweb.sci.gsfc.nasa.gov (accessed March 25, 2021).

URL: https://www.ngdc.noaa.gov/stp/space-weather/solardata/solar-features/solar-radio/radio-bursts/reports/fixedfrequency-listings (accessed February 1, 2021).

How to cite this article

Demyanov V.V., Yasyukevich Yu.V. Space weather: risk factors for global navigation satellite systems. Solar-Terrestrial Physics. 2021. Vol. 7. Iss. 2. P. 28-47. DOI: 10.12737/stp-72202104 